\title{
حظر تجنيا الأطفال أثناء النزاعات المسلحة في ضوء أحكام القانون الدولي
}

\author{
Doi: $10.23918 /$ ilic2020.36 \\ م.م. ليلى عيسـى ابوالقاسم \\ - جامعة جيهان اربيل - كلية القانون و العلاقات الدولية. قسم القانون \\ laylalayla630@gmail.com
}

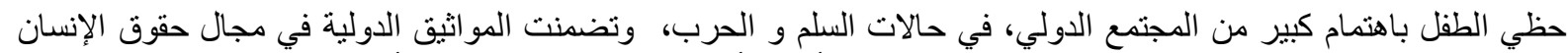

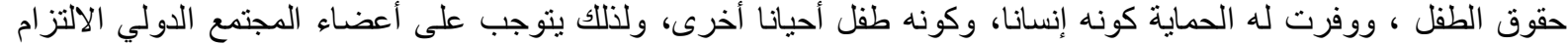

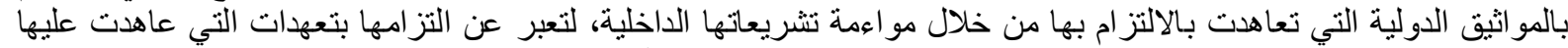

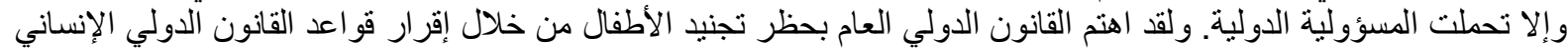

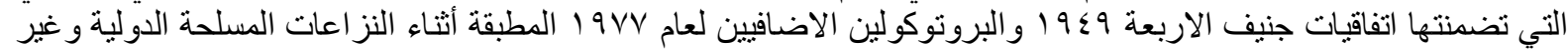

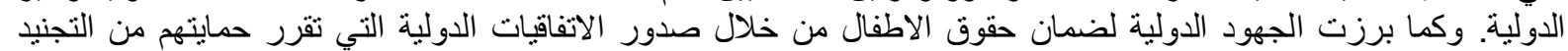

و والزج بهم في العمليات العدائية.

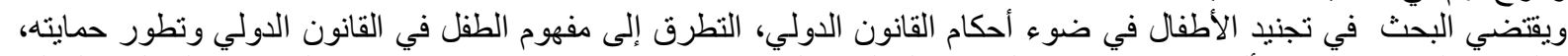

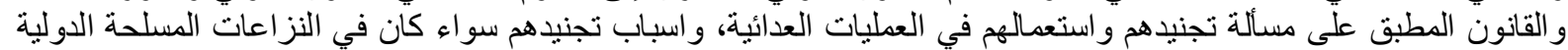

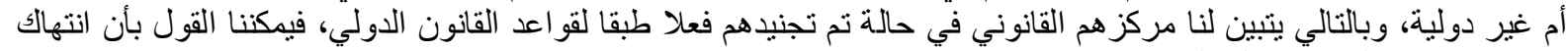

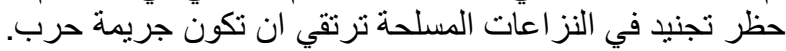

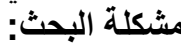

تكمن مشكلة البحث في بيان أحكام القانون الدولي التي تحظر تجنبد الأطفال أثناء النزاعات المسلحة، والحماية الكافية لهم كجزء

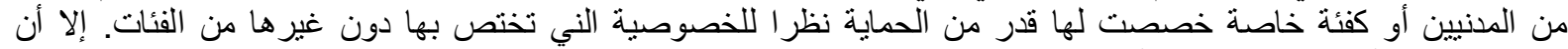

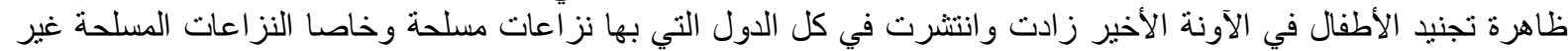

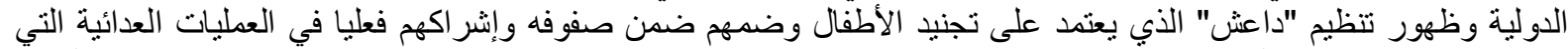

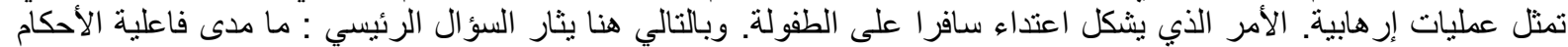

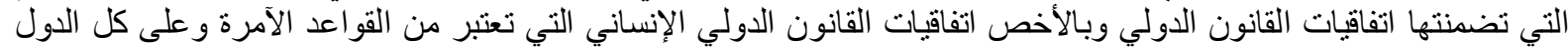

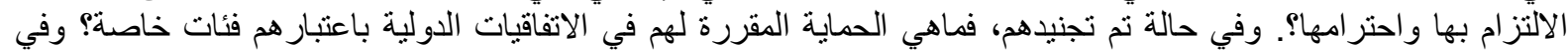

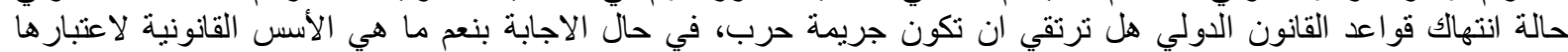

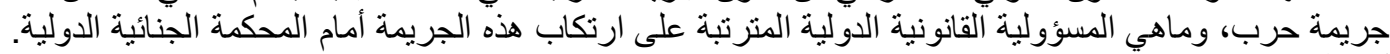

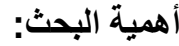

تستمد أهمية البحث من ظاهرة انتشار النزاعات المسلحة الدولية وغير الدولية ، وبروز ظهاهرة تجنيد الأطفال في النزاعات النهات

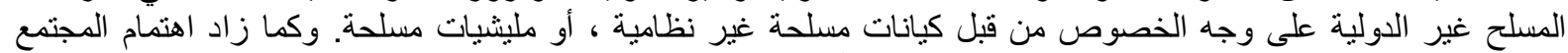

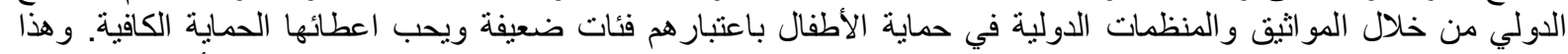

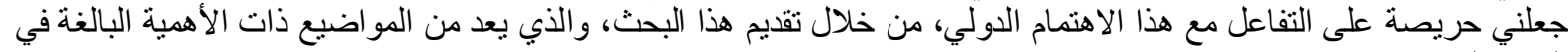

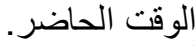

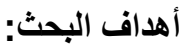

اــ الهدف من هذا البحث هو بيان قواعد القانون الدولي الانساني التي تحظر تجنيد الاطفال اثناء النزاعات المسلحة، وكيف

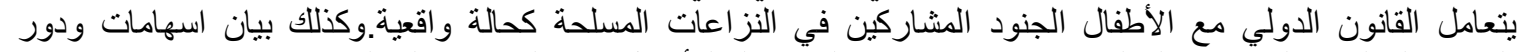

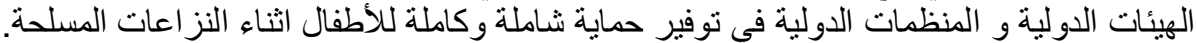

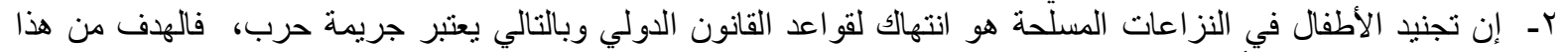

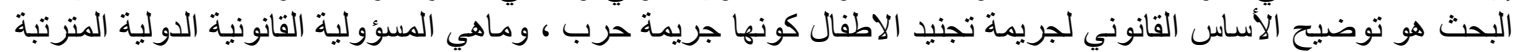

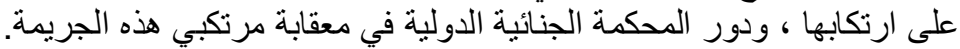

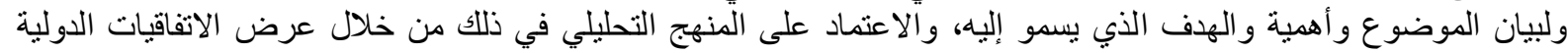

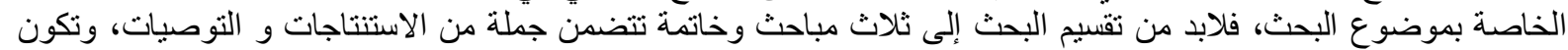

المباحث على النحو التالي:

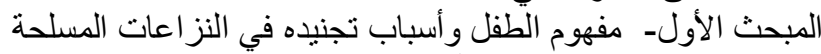

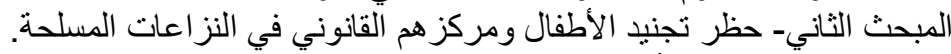

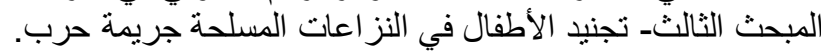

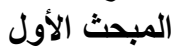

مفهوم الطقل وأسباب تجنيده في النزاعات المسلحة

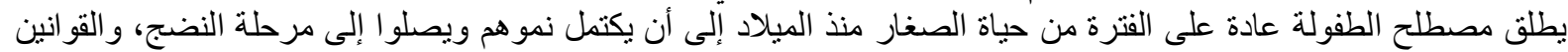

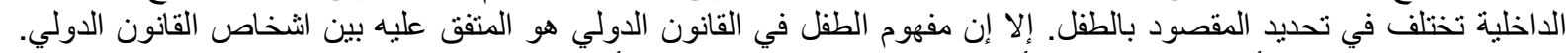

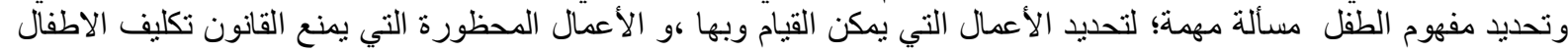


بها، وخاصا التي يكون أثر ها يسبب اضرار جسيمة على حياة الأطفال. كالتجنيد و اشر اكهم في العمليات العدائية اثناء النزاعات المسلحة.

وفي هذا المبحث سنوضح مفهوم الطفل في القانون الدولي وأسباب التجنيد في المطلب الأول ، وتصنيف النزاعات المسلحة التي المطلب الأول: مفهوم الطقل وأسباب تجنيده: يتم تجنيد الأطفال كمقاتلين في المطلب الثاني. أولا- تعريف الطقل والطقل المجند في المواثيق الاولية:

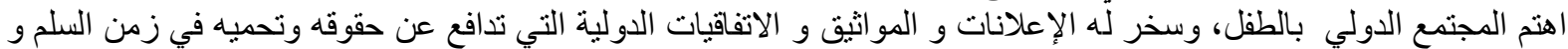

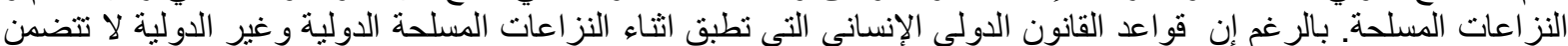

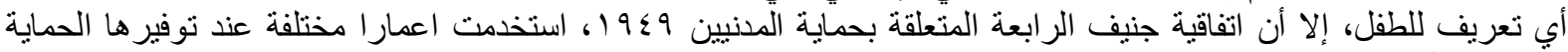

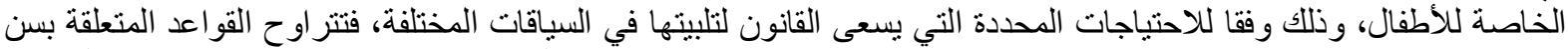

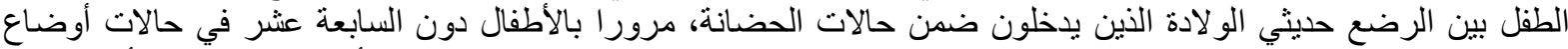

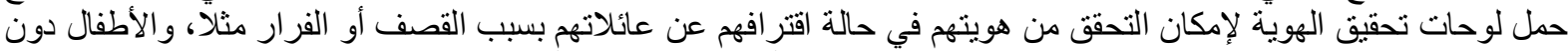

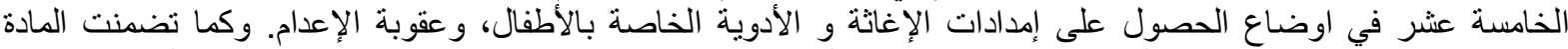

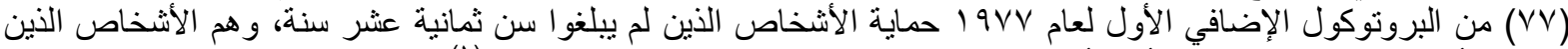

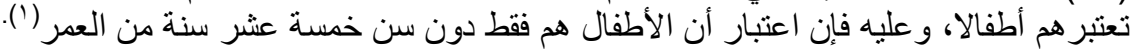

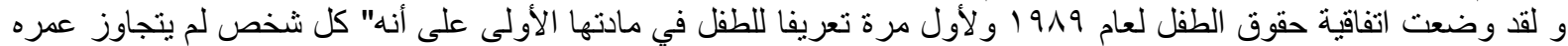

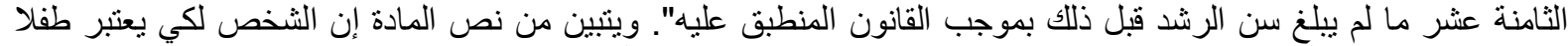

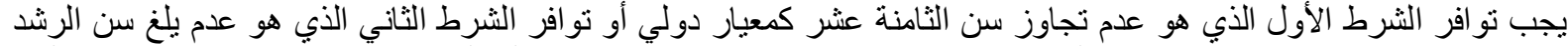

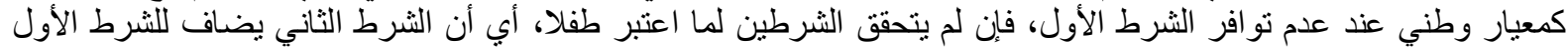

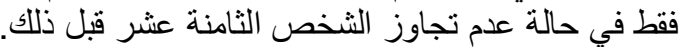

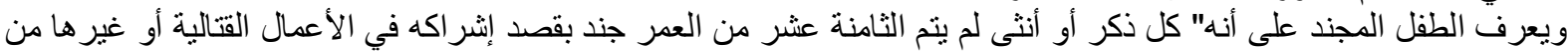

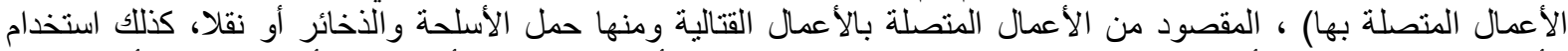

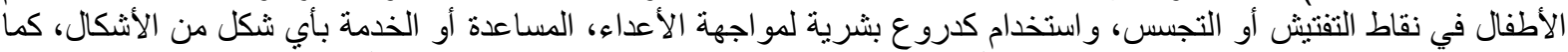

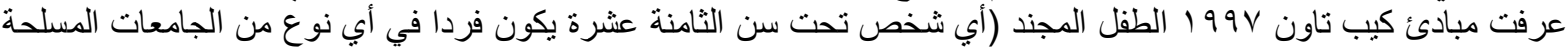

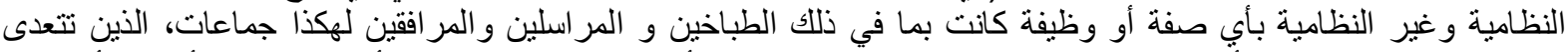

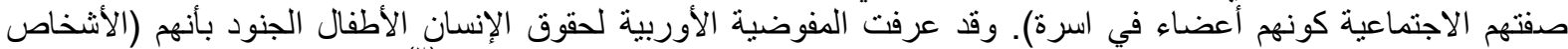

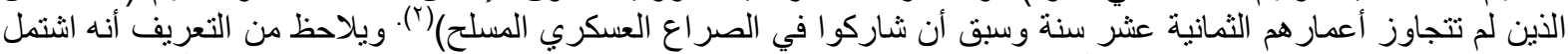

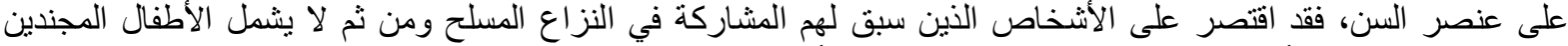

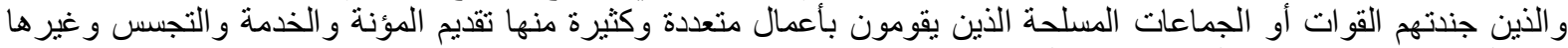

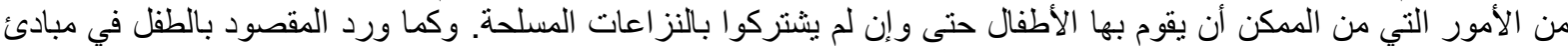

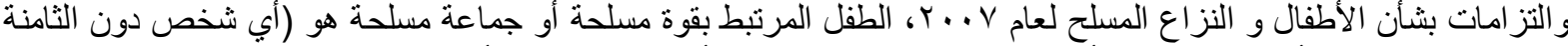

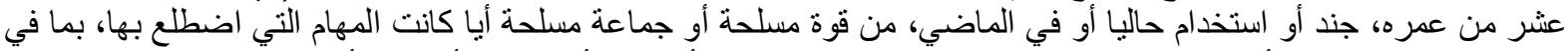

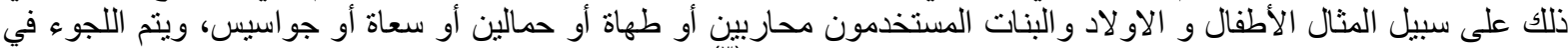

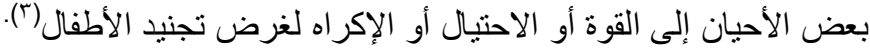

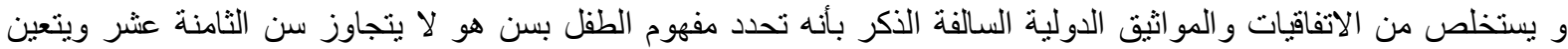

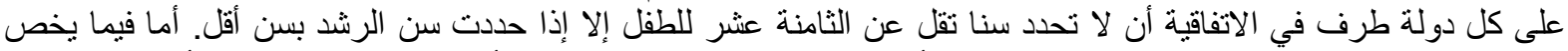

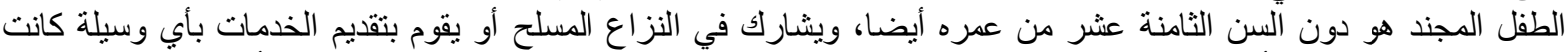

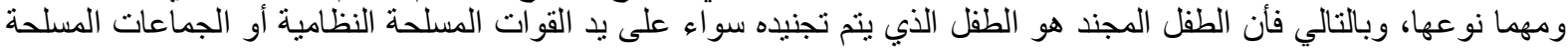

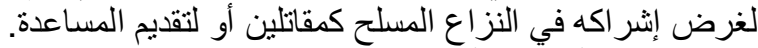
تانيا- تجنيا الأطفال و أسبابه:

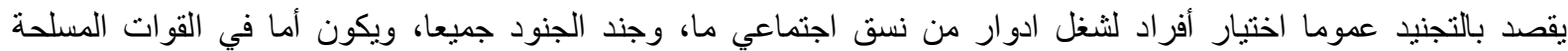

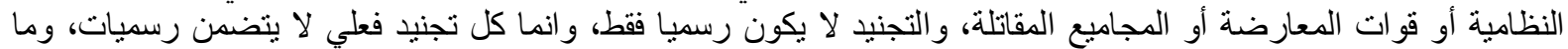

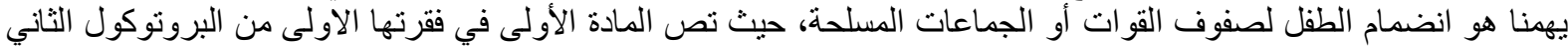

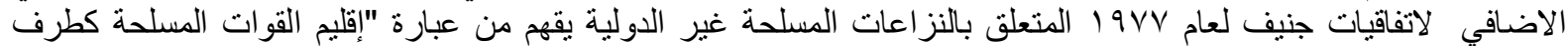
متعاقد سام"، كل القوات المسلحة بما فيها القوات التي قد لا بطلق عليها في إطار بعض النظم الوطنية "قوات التئ نظامية" و التي تشكل وفق القو انين الوطنية.

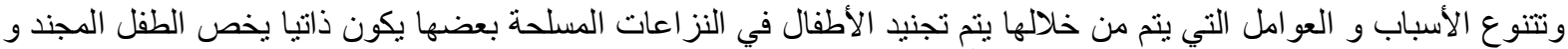

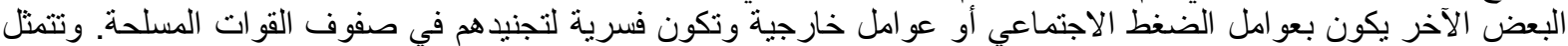

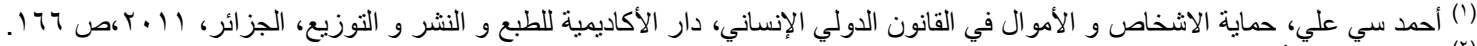

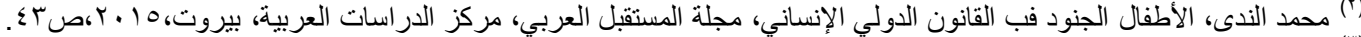

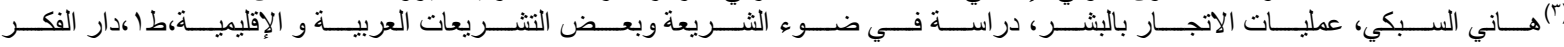

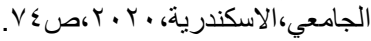


الأسباب الذاتبة التي تدفعه إلى الالتحاق بصفوف الجماعات المسلحة أو القوات الحكومية، هي دو افع مادية اقتصادية و اخرى الإق

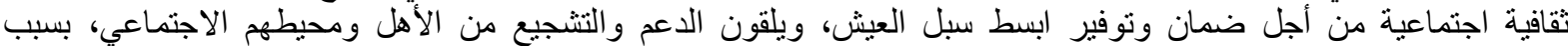

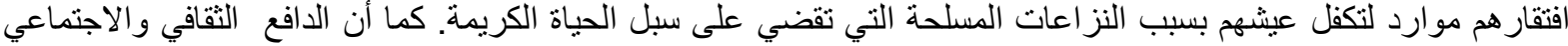

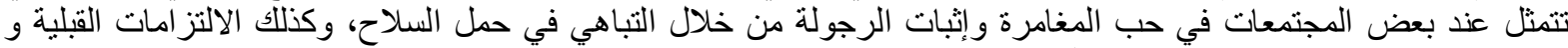

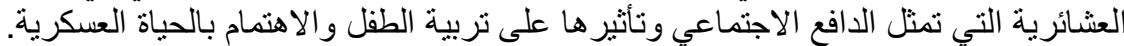

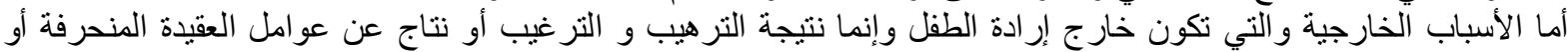

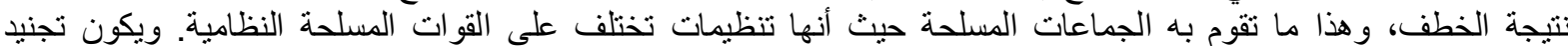

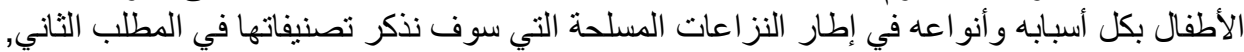
المطلب الثاني : تصنيف النزاعات المسلحة :

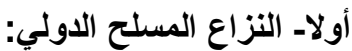

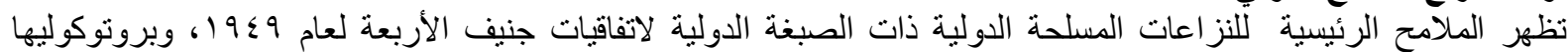

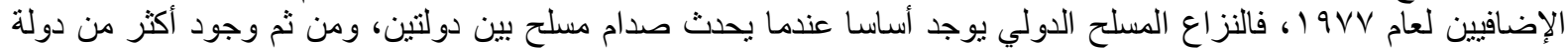

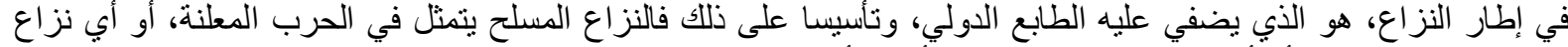

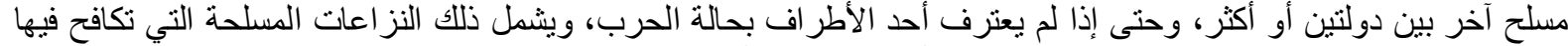

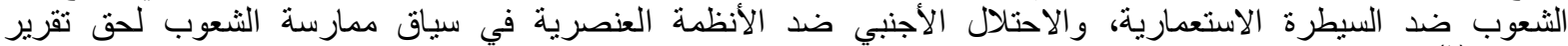

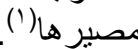

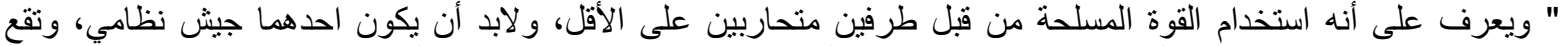

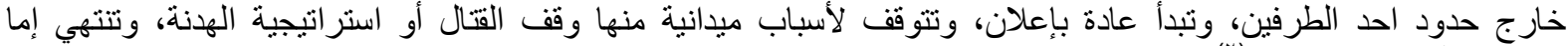

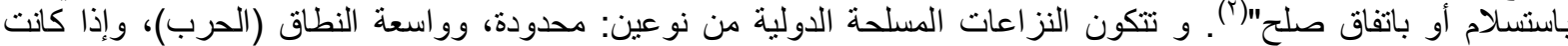

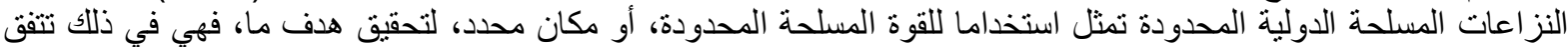

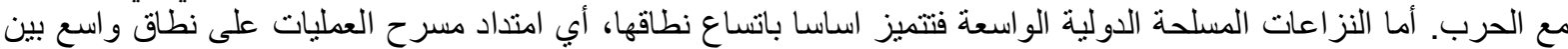

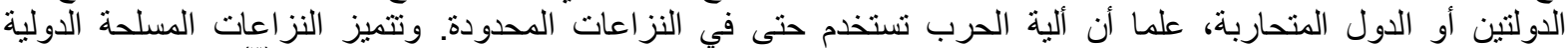

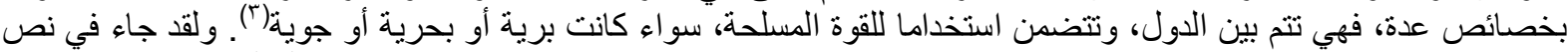

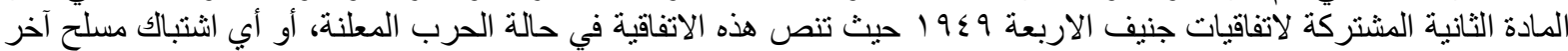

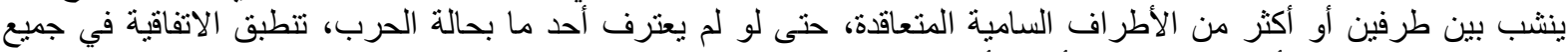

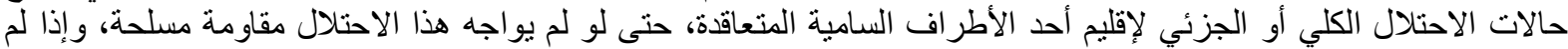

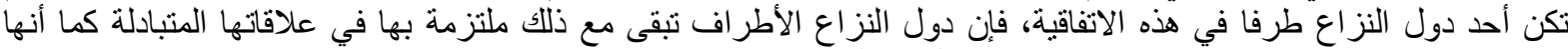

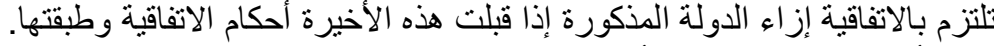

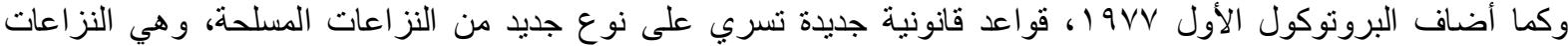

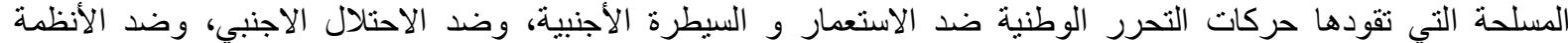

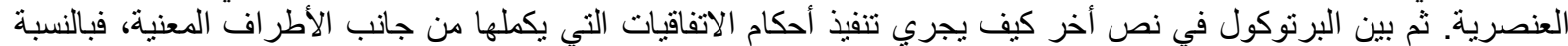

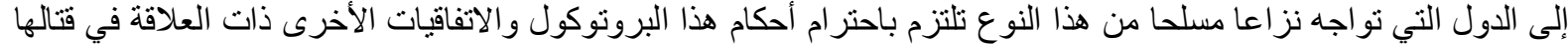
مع حركات التحرر الوطنية.

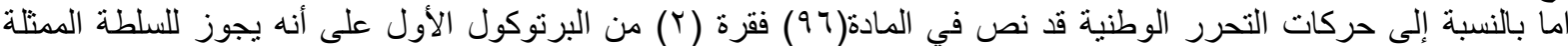

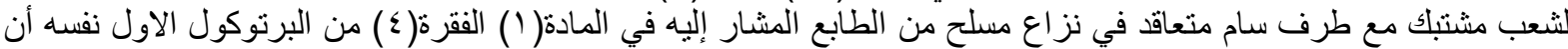

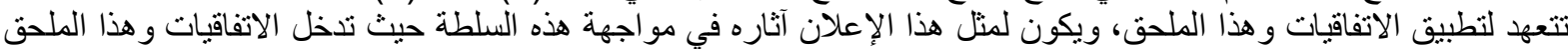

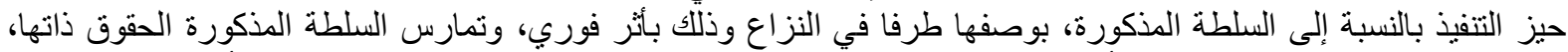

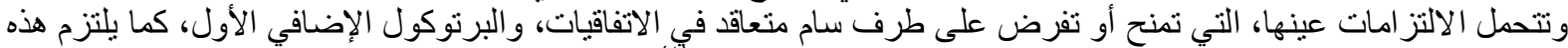

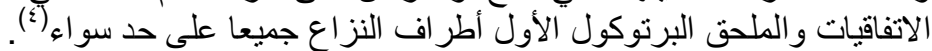

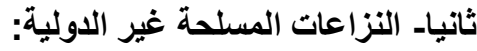

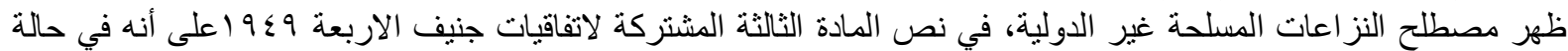

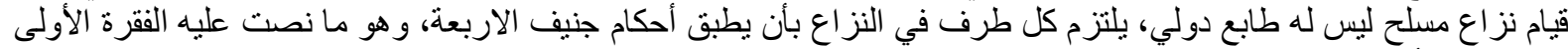

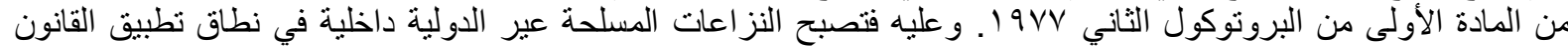

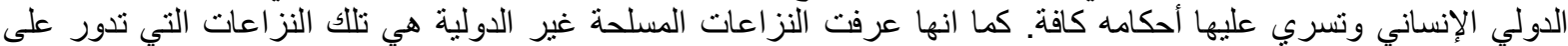

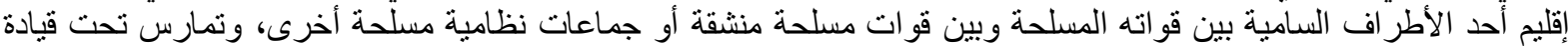
مسؤولة عن جزء من إقليمه من السيطرة ما يمكنها من القيام بعمليات عسكرية منسقة، وتسنطيع تنفيذ هذا البرتوكول. و لا تعد

(') خليل العبيدي حمايـة المـنيين في النزاعـات المسلحة الدوليـة في القانون الدولي الإنساني والثريعة الاسـلامية، رسـالة دكتور اه، غير منشورة، جامعة

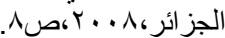

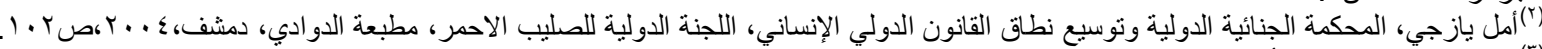
(")

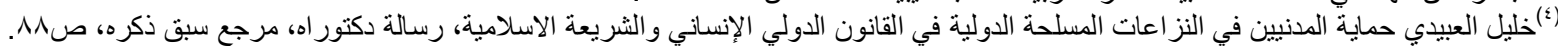


أعمال الثعب، والعنف و الاضطر ابات و التمرد و العصيان نزاعات مسلحة غير دولية وتسري عليها قواعد الفانون الدولي

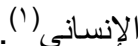

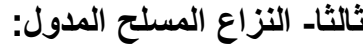

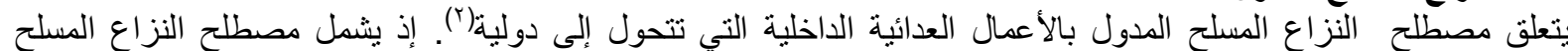

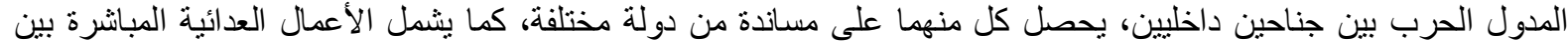

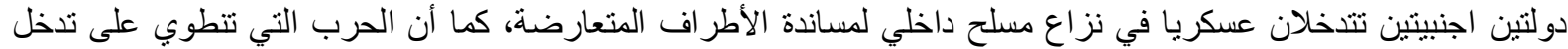

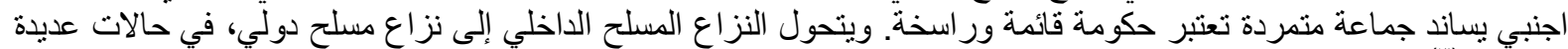

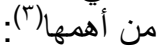
اــ ـ عند النظر إلى أنثاره المترتبة، إذا انتصر الثوار أو المتمردين في هذه الحالة قد تظهر دولة جليدة في حالة إذا كان الهدف من

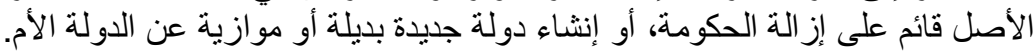

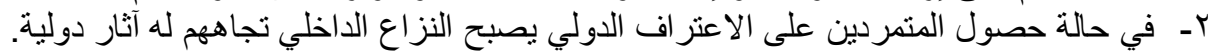

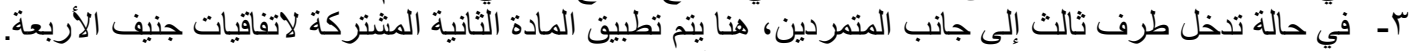

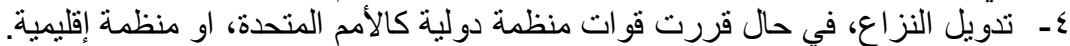
كل التصنيفات القانونية السابقة الذكر للنزاعات التات المسلحة يقابلها قو اعد قانونية في القانون الدولي الإنساني تتضمن الحماية الحماية لضحايا النزاعات المسلحة و بالأخص الطفل وكما تحظر من تجنيده والمشات المشاركة الفعلية فيها.

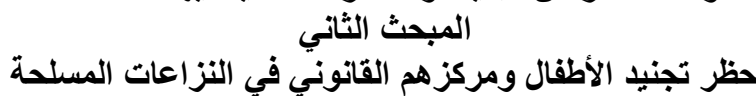

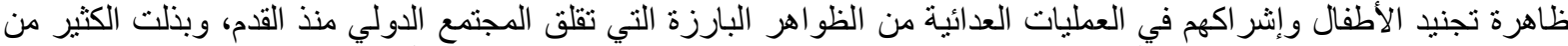

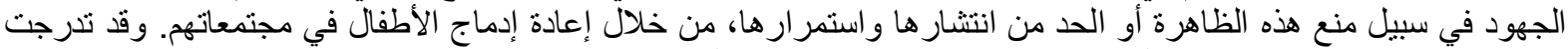

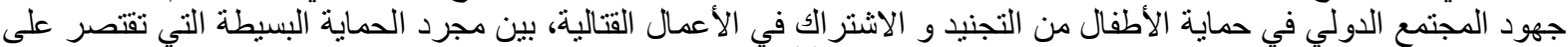

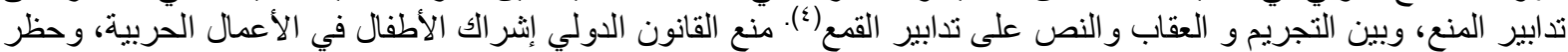

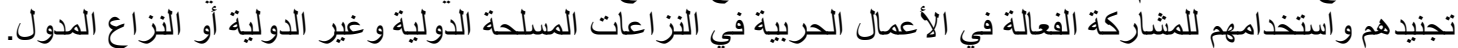

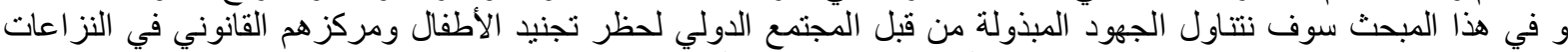

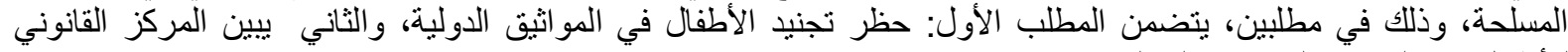

المطلب الأول: حظر تجنيد الأطفال في المواثيق الدولية: للأطفال كمقاتلين في النزاعات المسلحة فينة

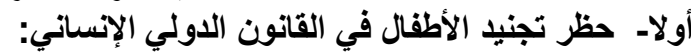

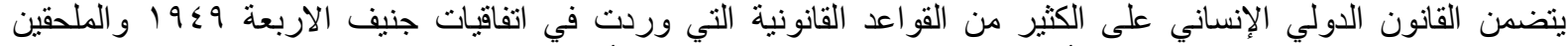

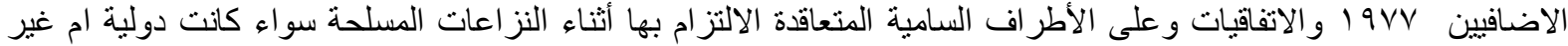

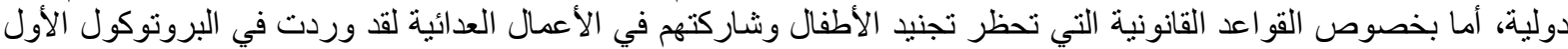

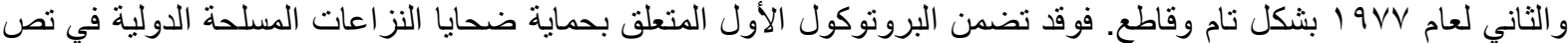

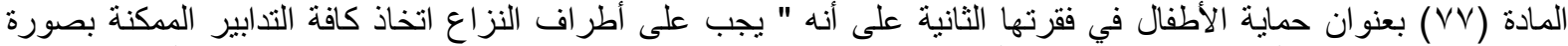

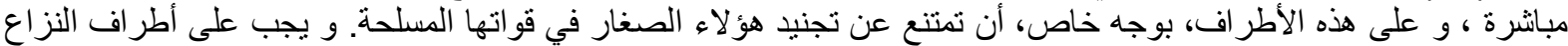

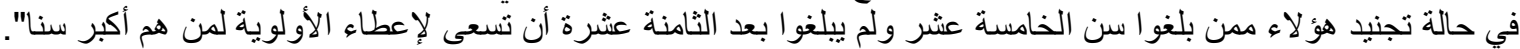

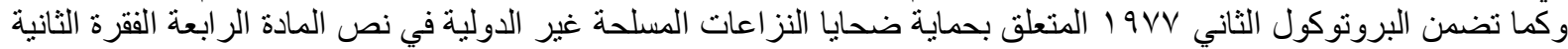

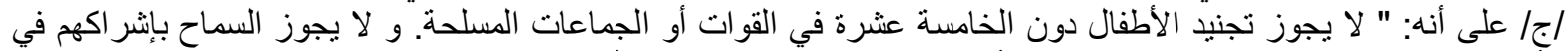

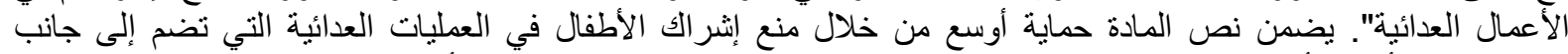

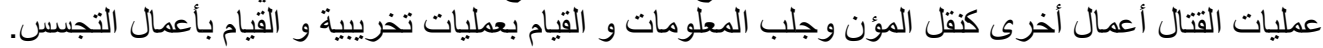

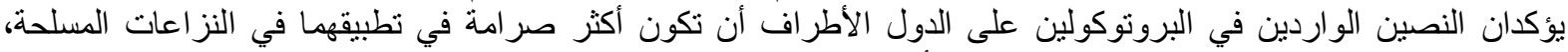

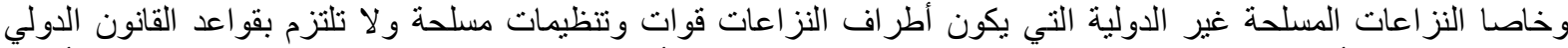

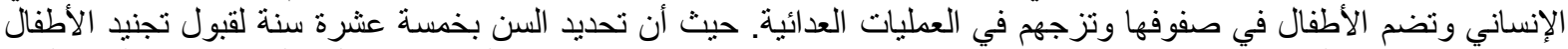
في القوات المقاتلة أو الإشراك في العمليات العدائية هو مكسب في حد ذاته لصالح الأطفال على أن يأخذ بالسن الأعلى أثناء تملية الانتقاء.

ثانيا- حظر تجنيا الأطفال في القانون الاولي العام:

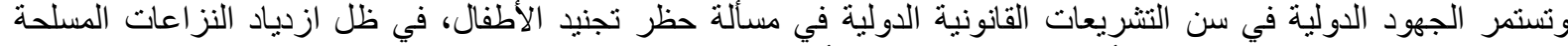

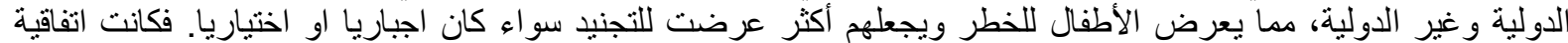

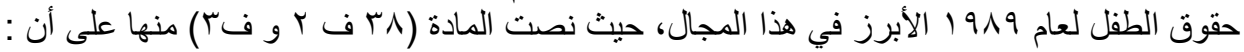

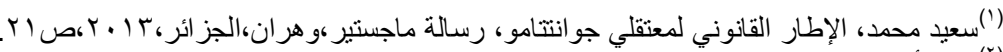

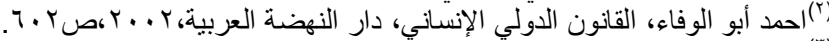

(")

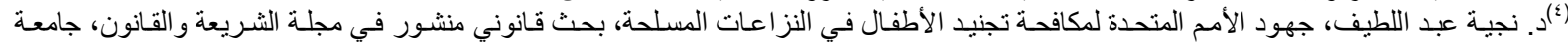

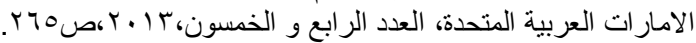


" اــ ـتخذ الدول الأطر اف جميع التدابير الممكنة عمليا لكي تضمن ألا يشترك الأشخاص الذين لم يبلغ خمس عشرة سنة اشتر اكا

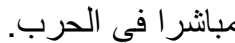
r- تمتنع الدول الأطر اف عن تجنيد أي شخص لم تبلغ سنه خمس عثرة سنة في قو اتها المسلحة، و عند التجنيد من بين الأشخاص

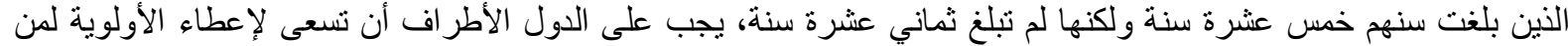
هم أكبر سنا.

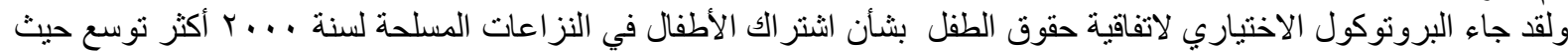

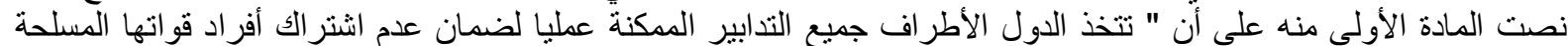

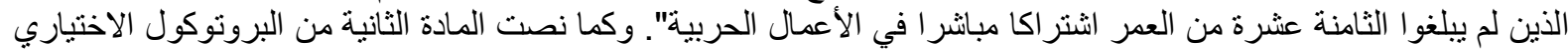

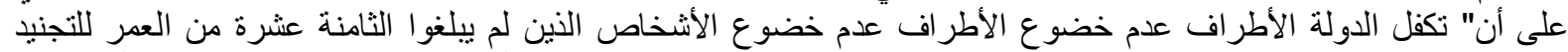

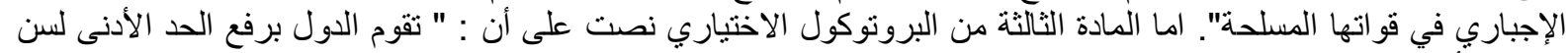

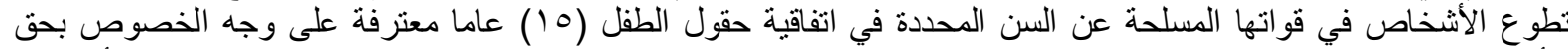
الأشخاص دون سن الأثامنة عثرة في حماية خاصة، وإذا كان هذا السن يقل عن ثمانية عثر عاما فيجب على على الدول أن تكفل

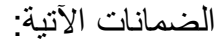

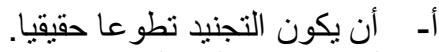

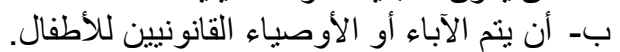

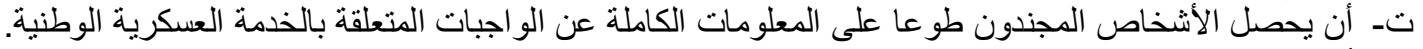

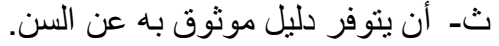

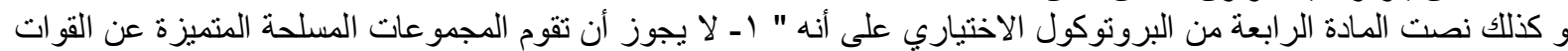

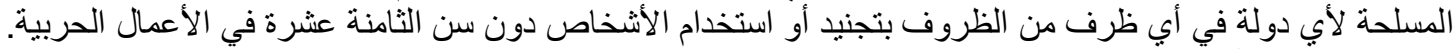

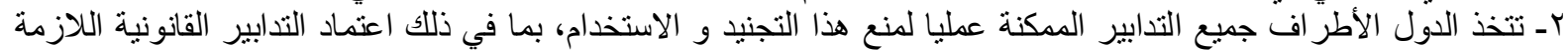
ل كظر وتجريم هذه الممارسات. وبما أن الطفل محل اهتمام وحماية من المجتمع الدولي في السلم و الحرب، اصدئ الصدرت منظمة العمل الدولية اتفاقية دولية خاصة

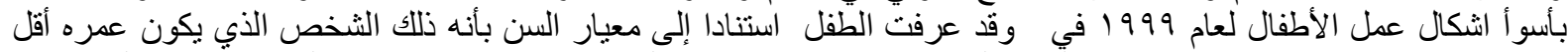

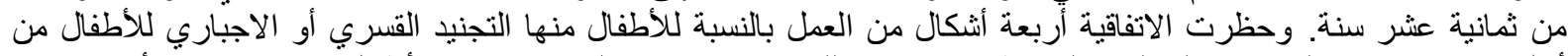

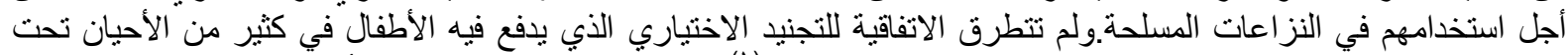

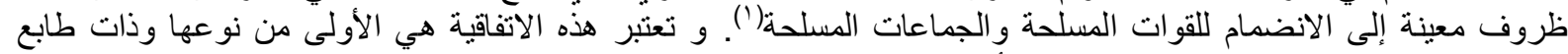

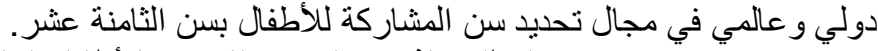

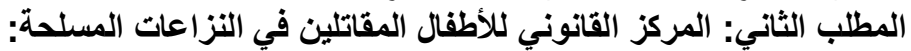

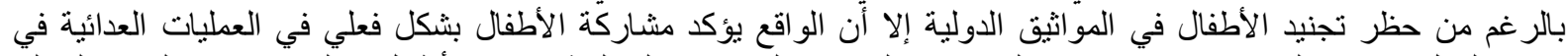

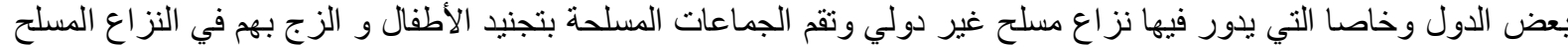

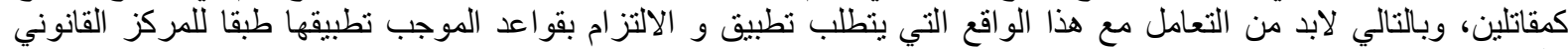

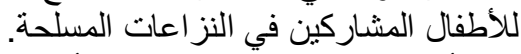

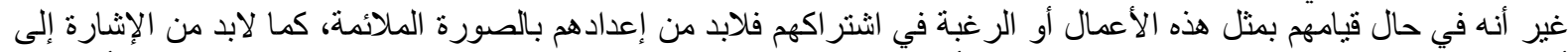

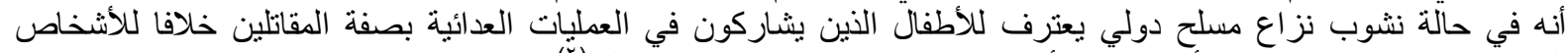

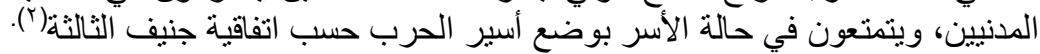

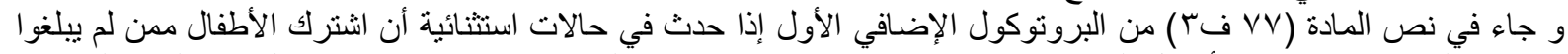

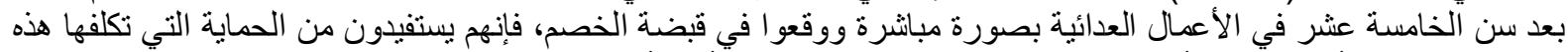

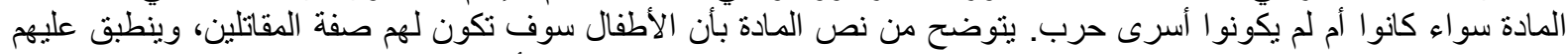

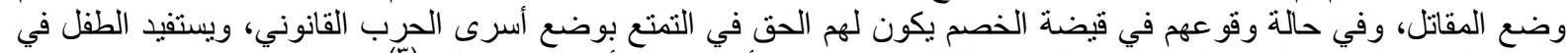

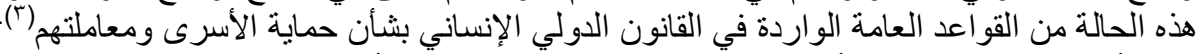

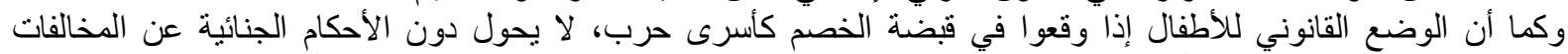

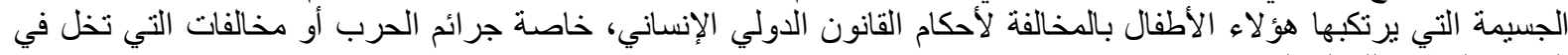

القانون الوطني للادولة الحاجزة.

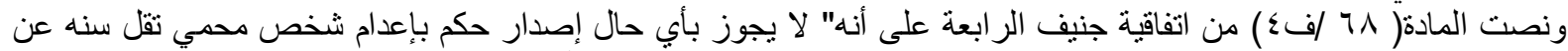

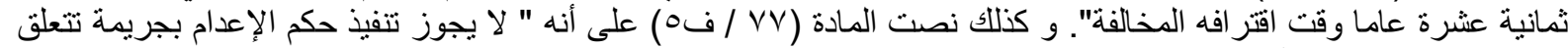

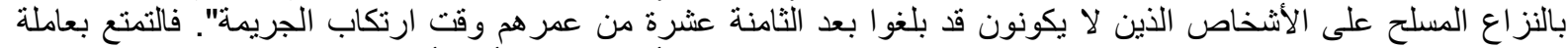

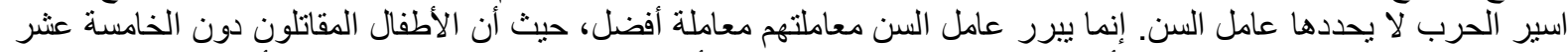

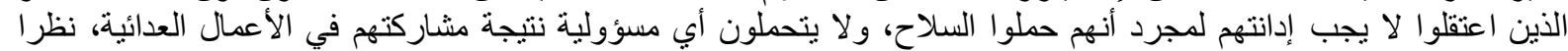

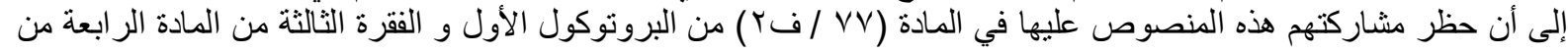

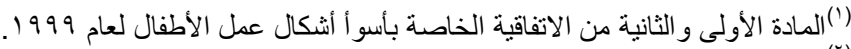

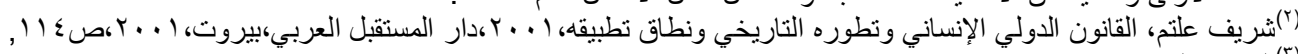

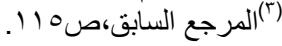


البروتوكول الثاني يخص أطر اف النزاع وليس الأطفال، فالمسؤولية في مثل هذه المخالفة تقع على سلطات الطرف المشارك في

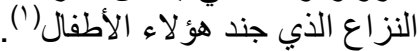
ونصت المادة (1) (1) من اتفاقية جنيف الثالثة على أنه " يفرج عن أسرى الحرب، ويعادون إلى أوطانهم دون إبطاء بعد انتهاء

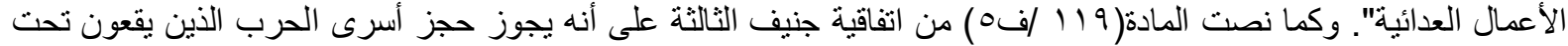

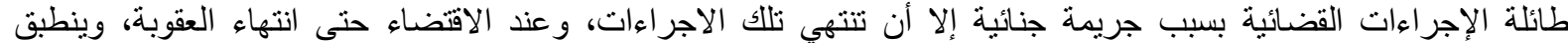

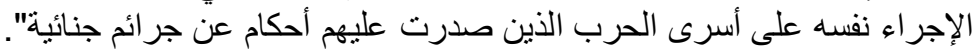

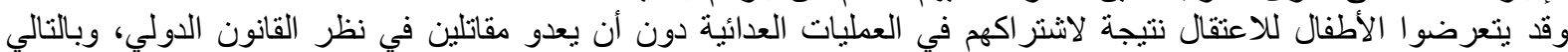

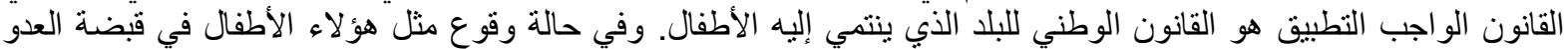

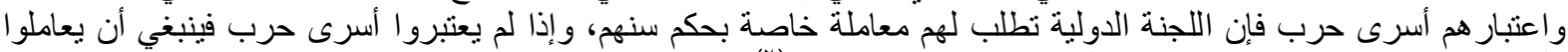

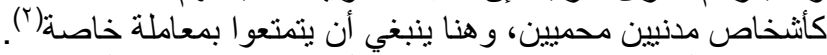

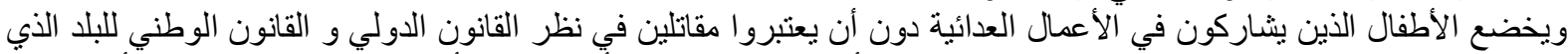

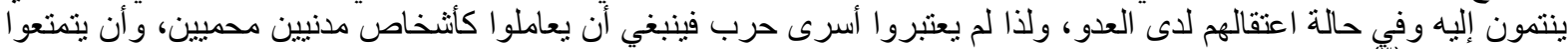

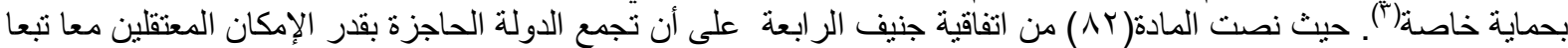

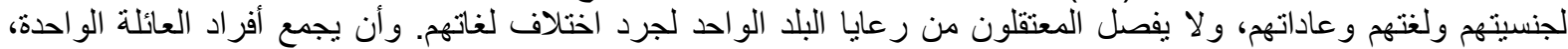

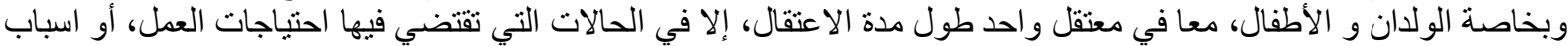

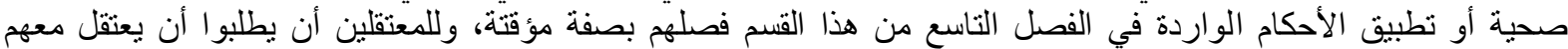

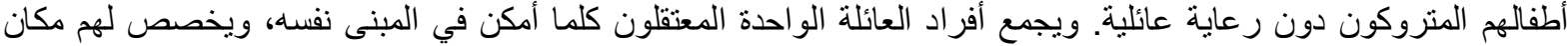

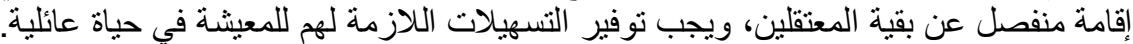

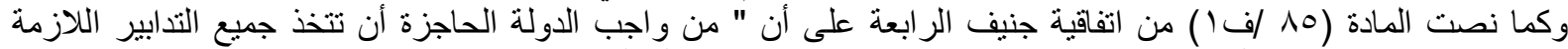

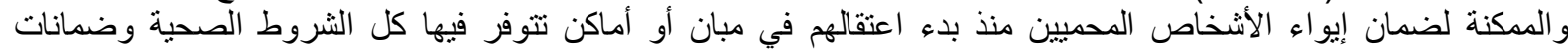

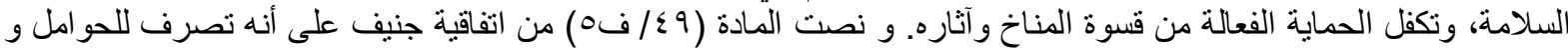

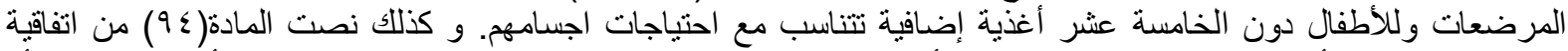

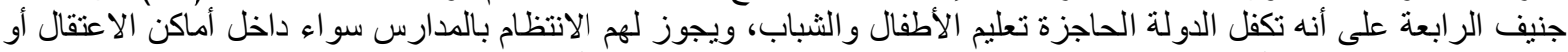

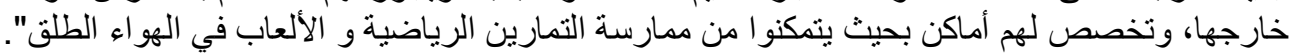

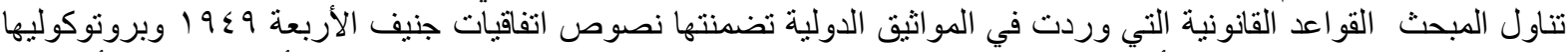

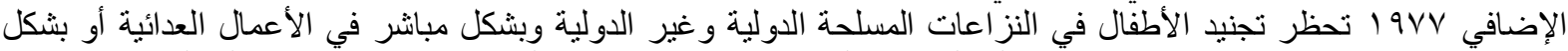

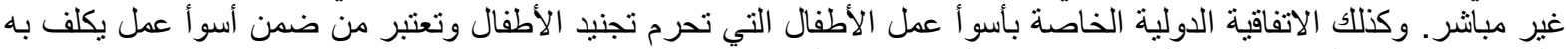

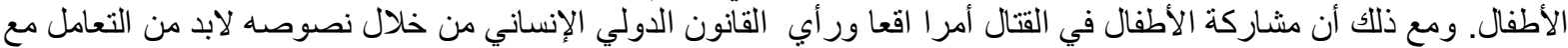

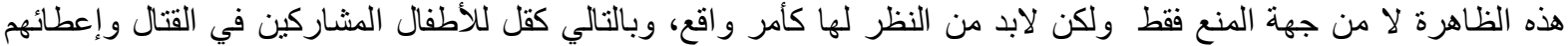

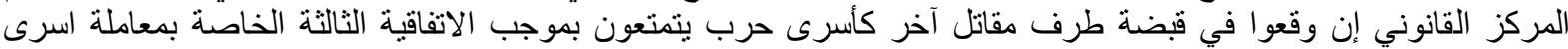

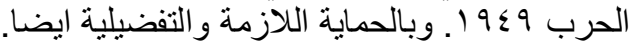

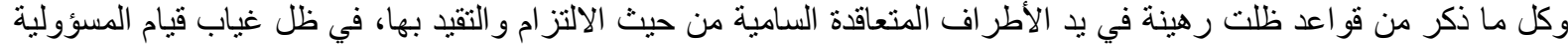

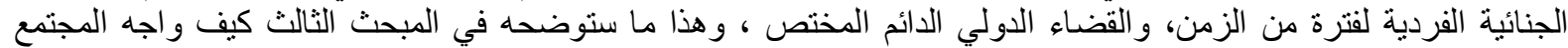

الدولي منتهي قو اعد القانون الدولي الإنساني.

\section{المبحث الثالث}

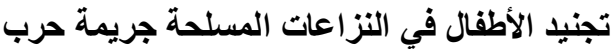

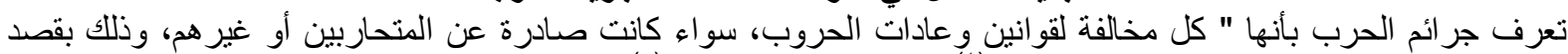

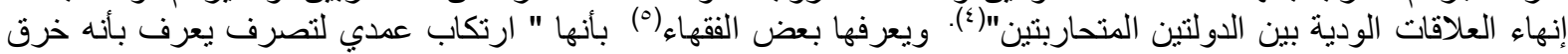

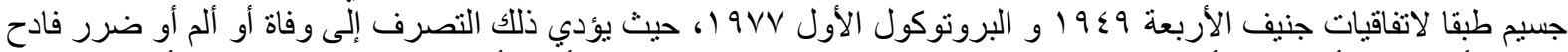

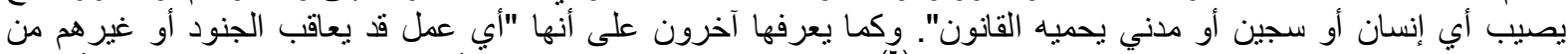

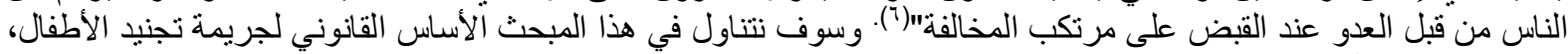

المطلب الأول: الأساس القانونة الجني لجريمة تجنيد الأطفال:

مسؤولية تجنيد الأطفال امام المحكمة الجنائية الدولية.

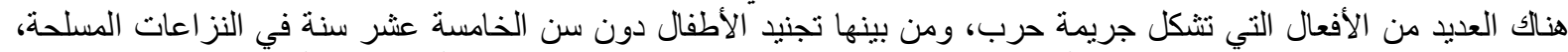

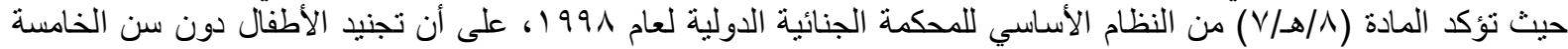

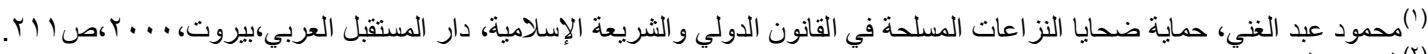

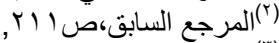

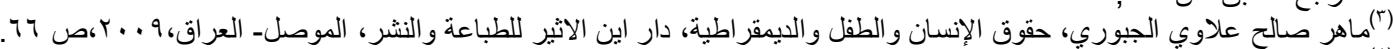

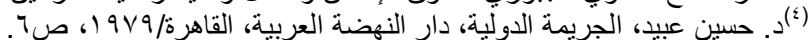

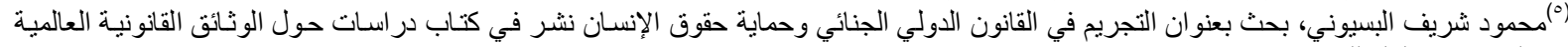

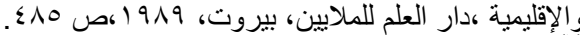

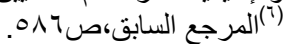




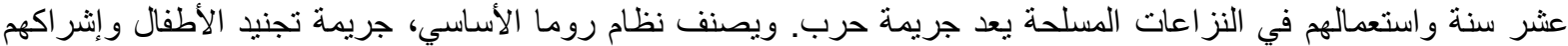

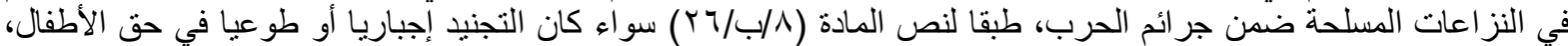

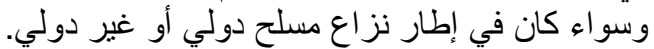

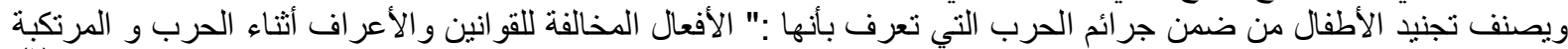

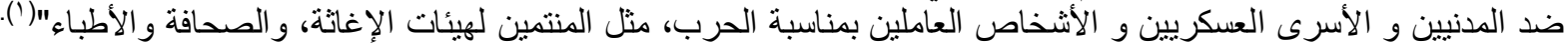

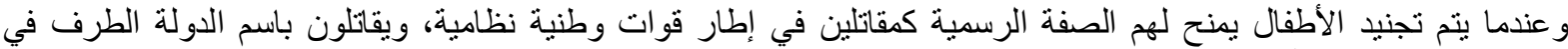

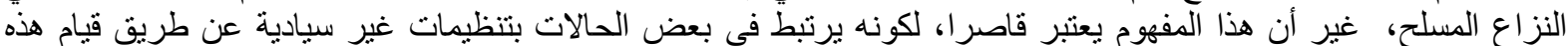

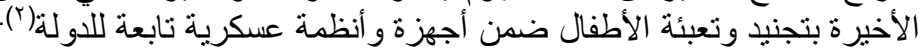

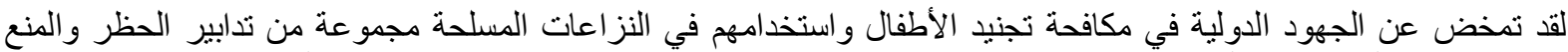

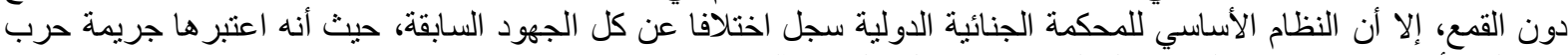

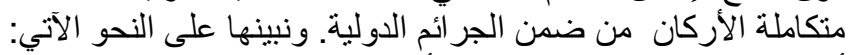

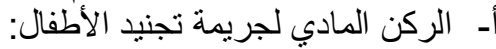

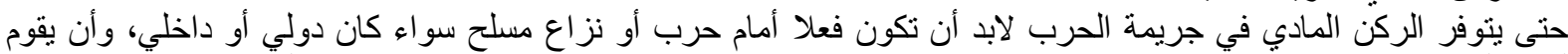

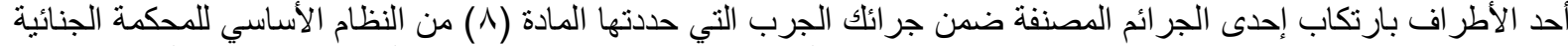

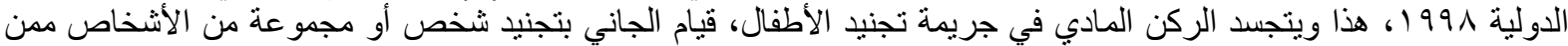

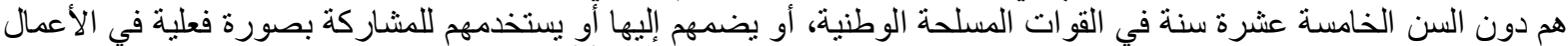

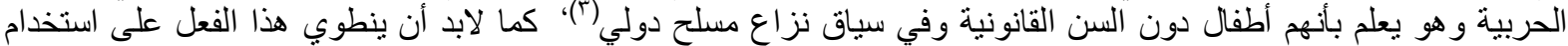

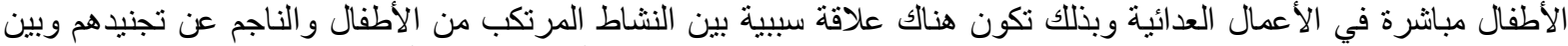

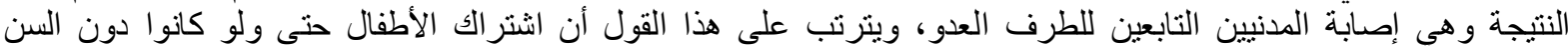

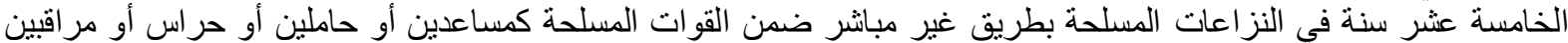

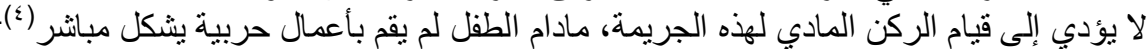

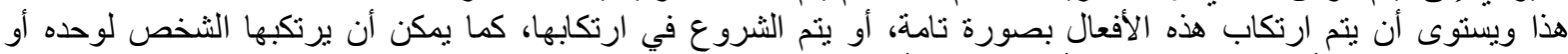

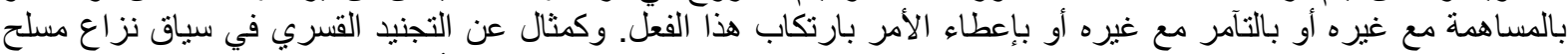

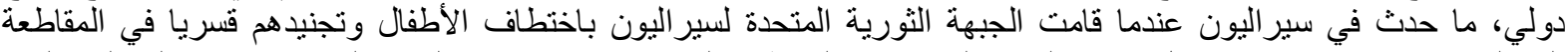

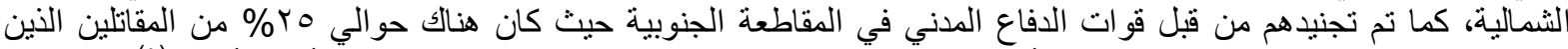

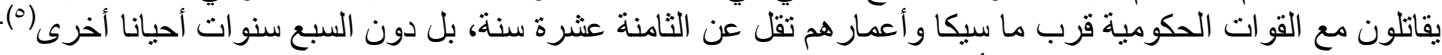
ب- بـ الركن المعنوي لجريمة تجنيد الأطفال:

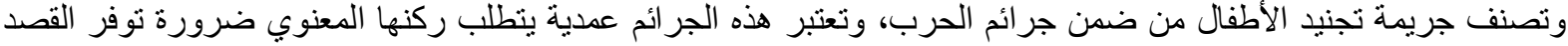

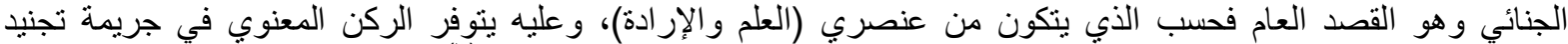

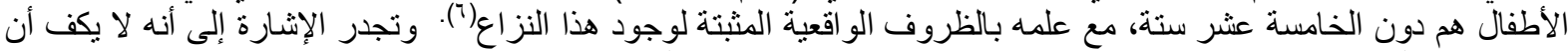

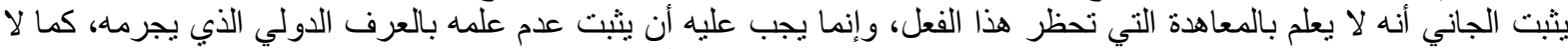
يكف لانتفاء العلم الامتتاع عن التوقيع على المعاهدة التي تحظر الفعل، إذ أن هذا الامتتاع في حد ذاته يؤكد سوء نية الدولة النها المبيتة

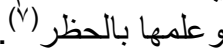
ج- الركن الدولي لجريمة تجنيد الأطفال:

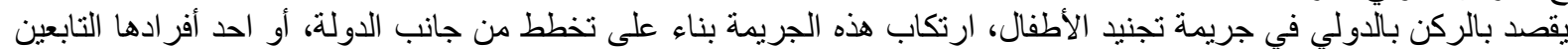

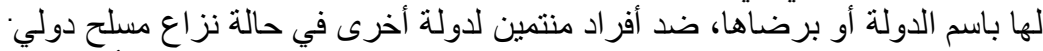

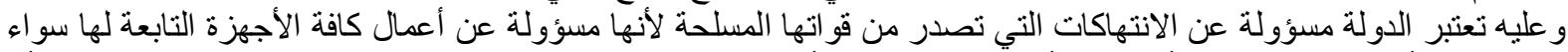

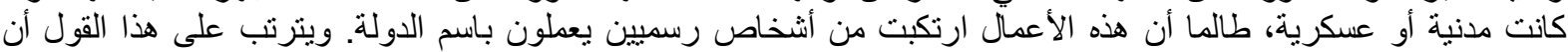

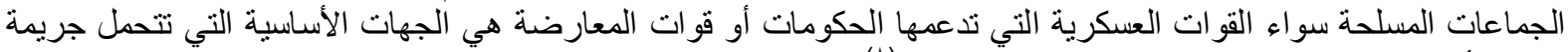

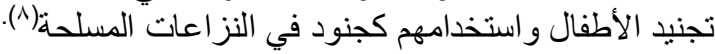

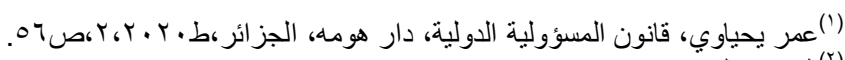

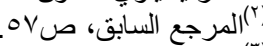

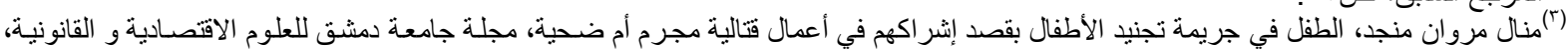

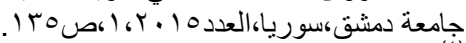

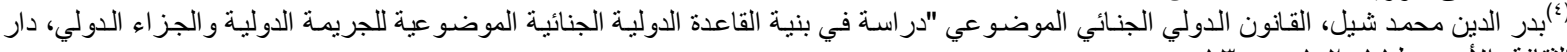

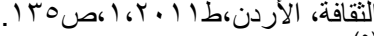

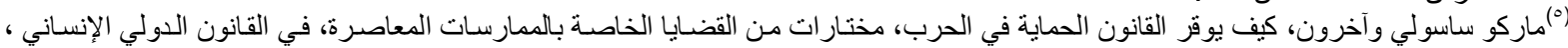

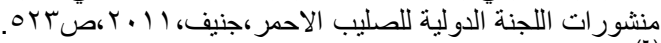

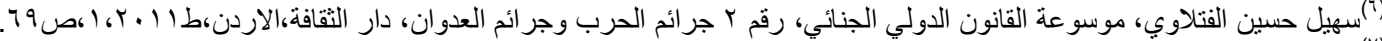

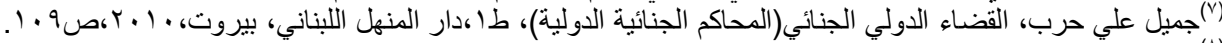

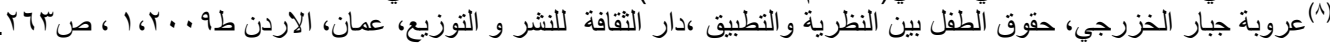




\section{المطلب الثاني: مسؤولية تجنيد الأطفال امام المحكمة الجنائية الدولية:}

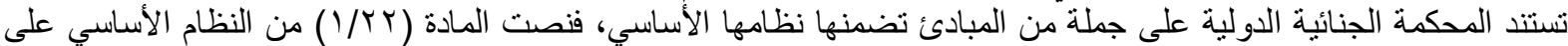

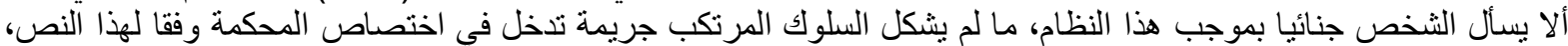

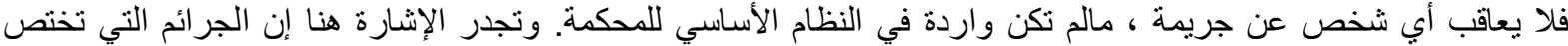

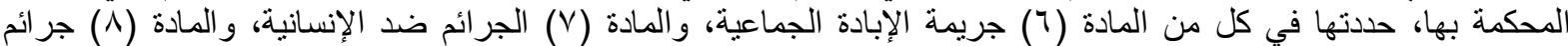

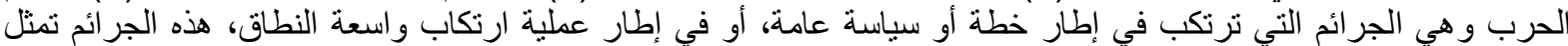

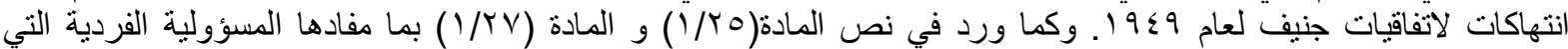

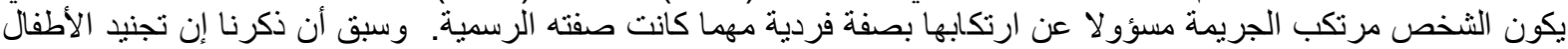

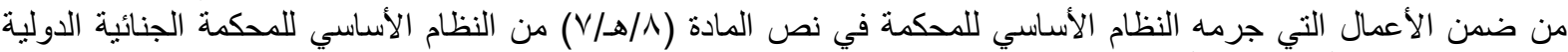

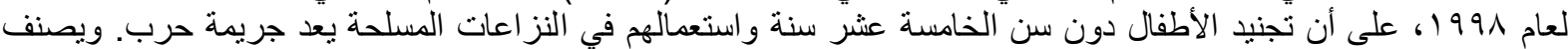

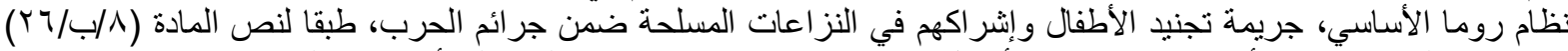

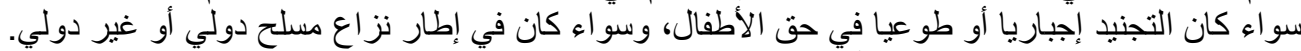

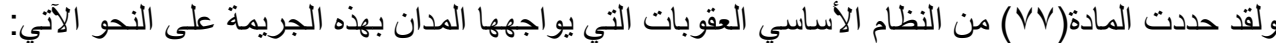

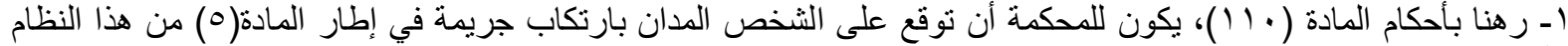

الأساسي إحدى العقوبات الآتية:

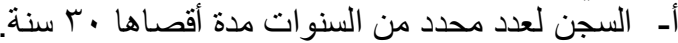

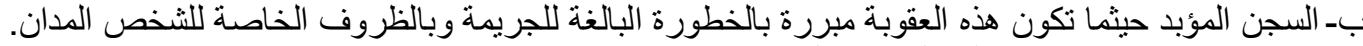

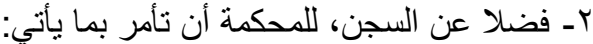

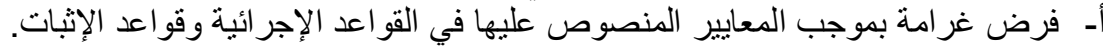
ب-مصادرة العائدات والممتلكات والأصول المتاتية بصورة مباشرة أو غير مباشرة من تلاتلك الجريمة دون المساس بحقوق الأطر اف الثالثة الحسنة النية. ولقد عرضت الكثير من القضايا التي لها علاقة مباثرة بتجنيد الأطفال في النزاعات المسلحة، فقي أحداث الكونغو، وخات وخاصة في

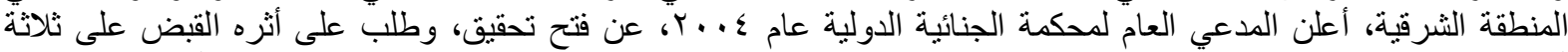

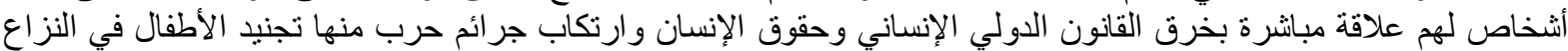

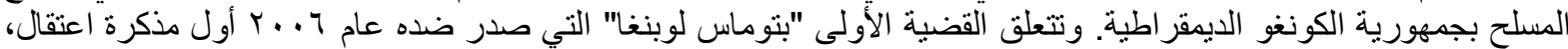

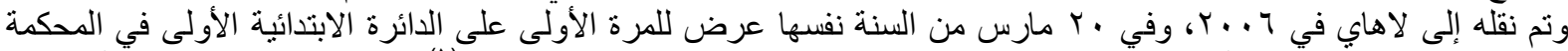

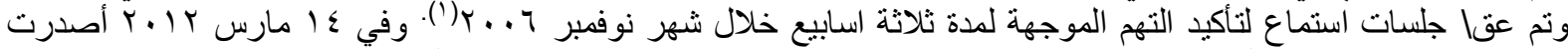

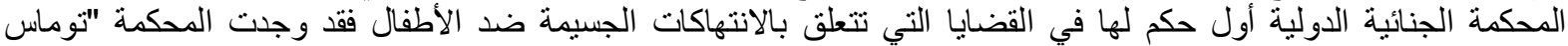

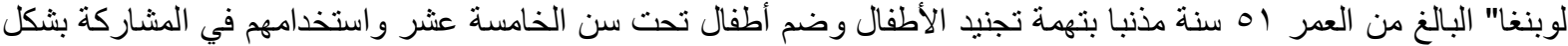

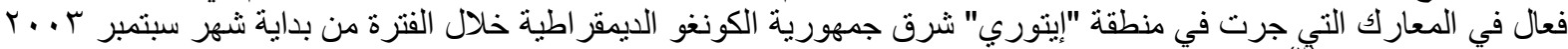

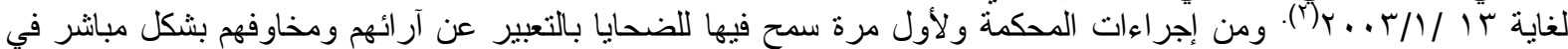

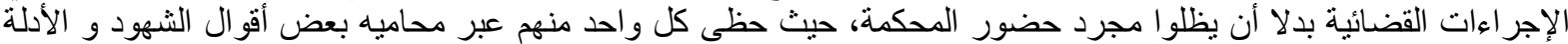

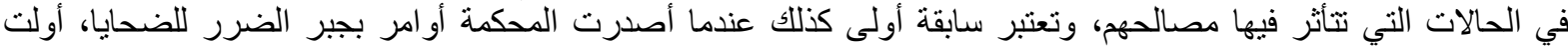

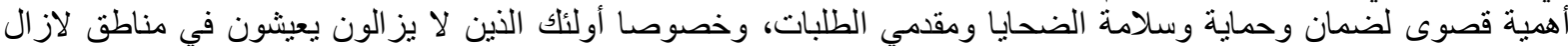

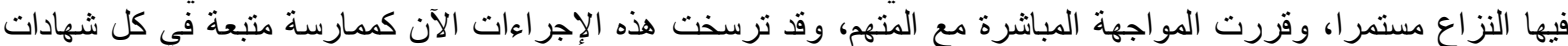

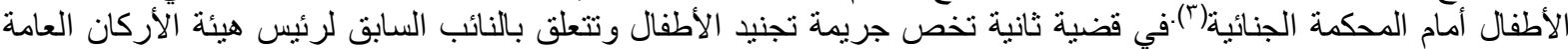

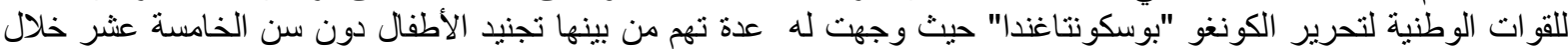

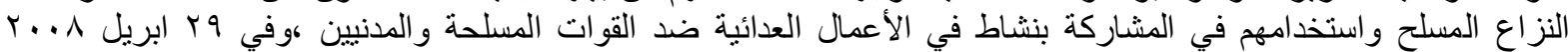

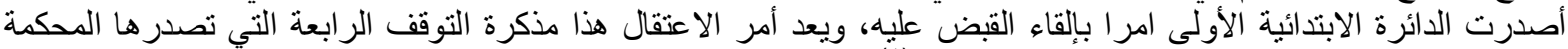

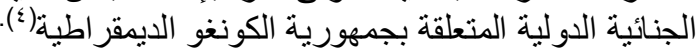

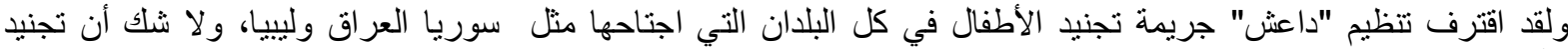

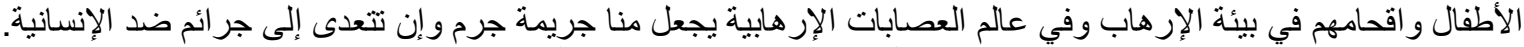

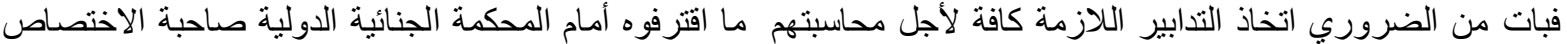

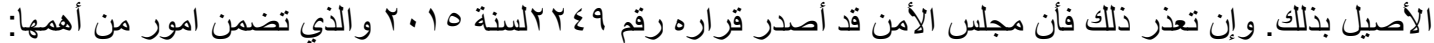

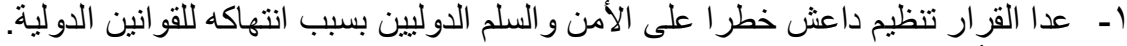

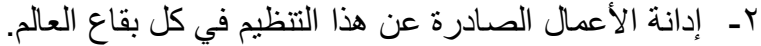

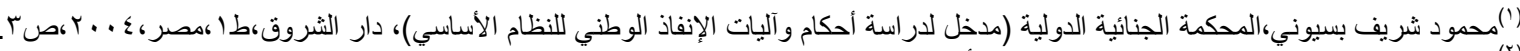

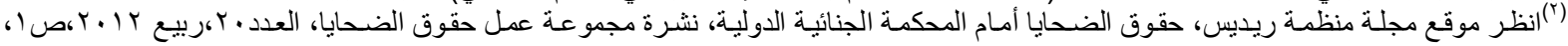

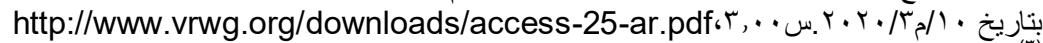

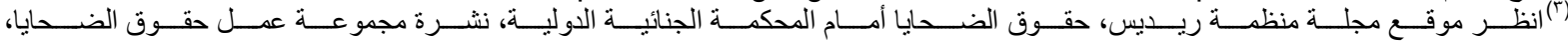

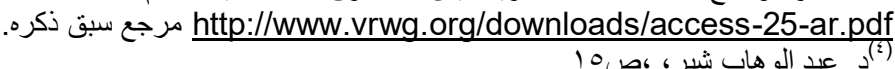


rــ ت تعاون الدول التز امها باتخاذ التدابير اللازمة لمحاربة الإرهاب وفقا لقو اعد القانون الدولي.

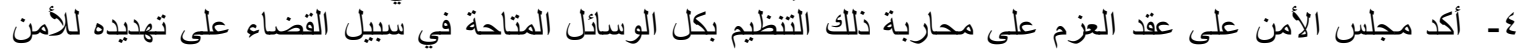

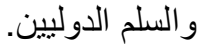

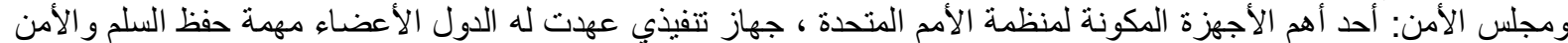

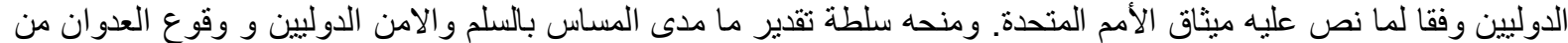

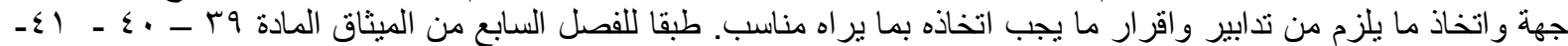

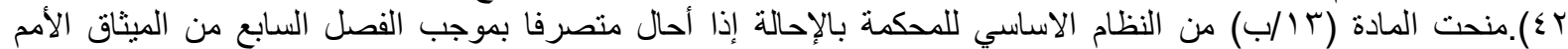

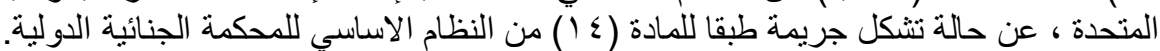

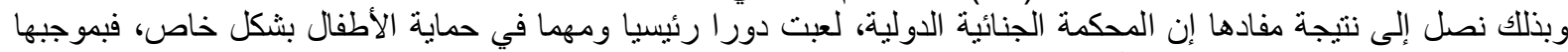

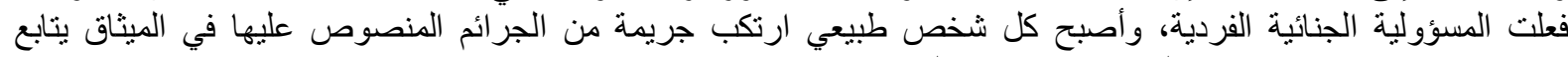
ويحاكم امامها مهما كان مركزه القانوني، و انصفت الضحايا بجبر ضرر هم بإنثاء صندوق التئئماني يخصهم. الخاتمة

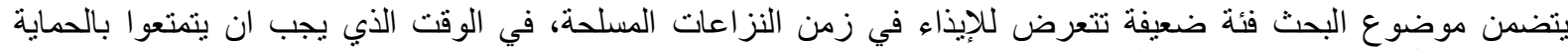

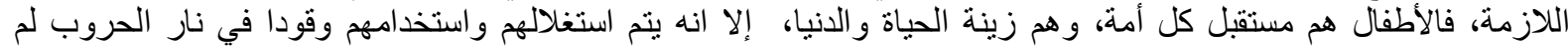
يكونو الببا فيها:.

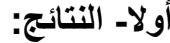

بعد عرض القتسيمات البحث وصلنا إلى نتائج مهمة حققها المجتمع الدولي تهدف إلى حماية الأطفال والإنسانية جمعاء، ونجملها في النقاط التالية:

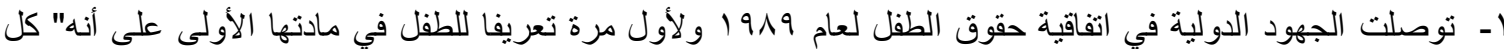

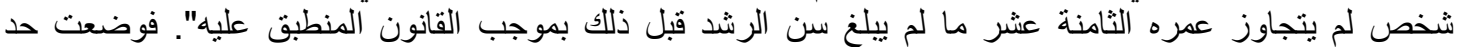

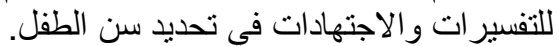

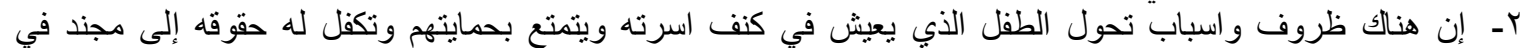

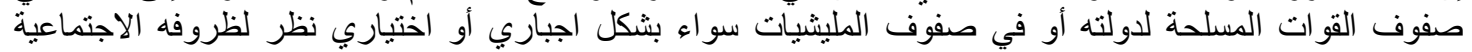
و والاقتصادية الصعبة.

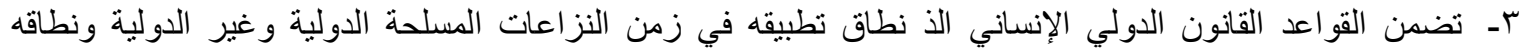

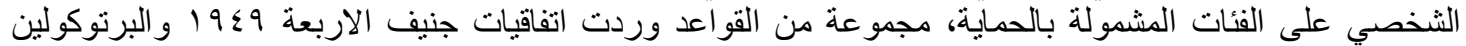

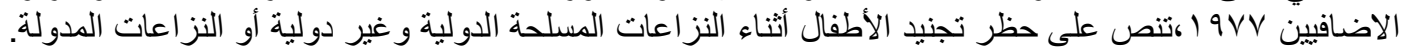

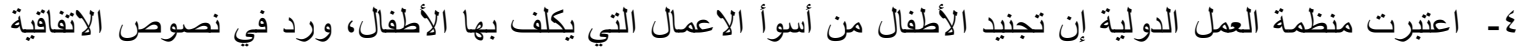

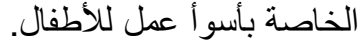
هـ ـ لم يخفل القانون الدولي الإنساني بأن الأطفال احتمالية مشاركتهم في التتال كمقاتلين او مساعدين وبالتالتالي يتمتعون بالحماية الواردة في اتفاقيات جنيف وبالأخص الفاقية جنيف الثالثة بشأن معاملة أسرى الحرب، و المعاملة الثانية التفضيلية

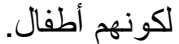

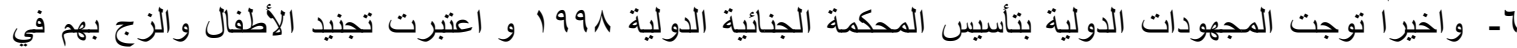

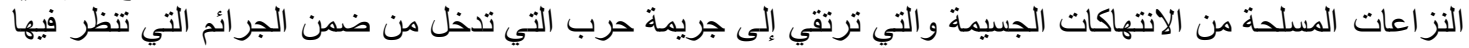

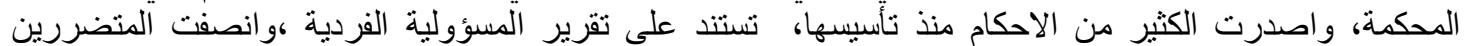

$$
\text { بتعو يضهم عن الضرر الذئي اصنابهم. }
$$

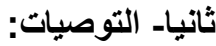

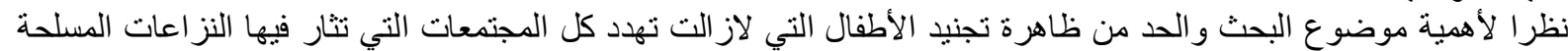

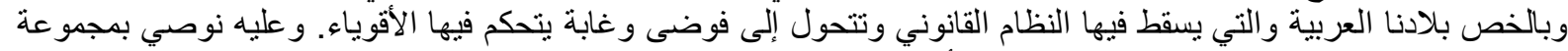

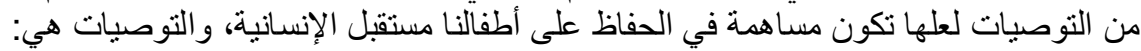

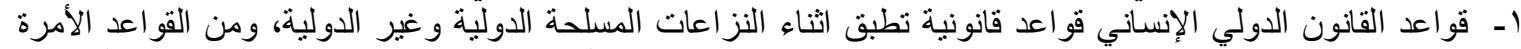

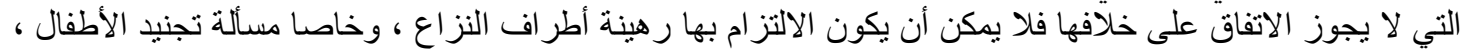

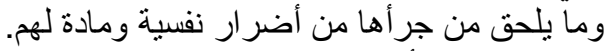

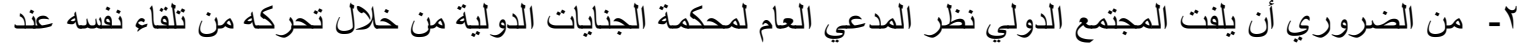

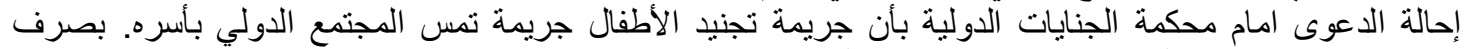

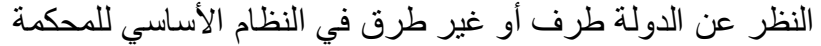

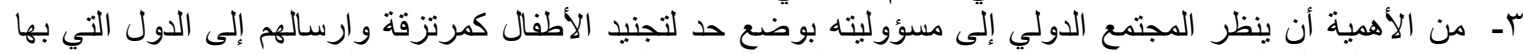

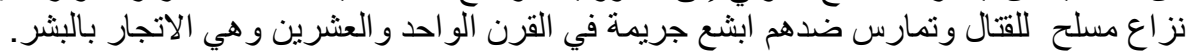

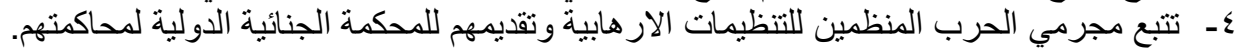

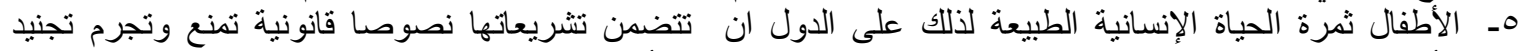
الأطفال سواء في السلم او الحرب مهما كانت الاسباب. وتحدد لهم أقصى عقوبة لمرنكبي هذا الجرم. 
آ- من الواجب أن تعمل الدول على تأمين حياة كريمة للطفل بين اسرته من خلال تسهيل سبل الحياة المعيشية لأسرته.

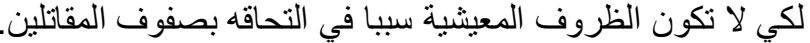

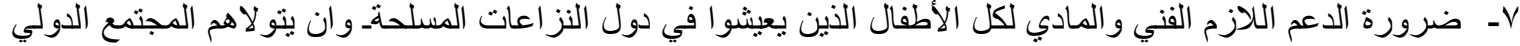
بالر عاية الحقيقة و اللازمة.

ي- ـ ضرورة التأكيد على دور المنظمات الحقوقية ومنظمات المجتمع الدولي و المؤسسات التربوية مساعدة الأطفال العائدين

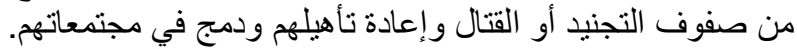

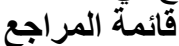

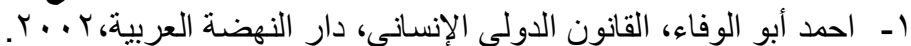

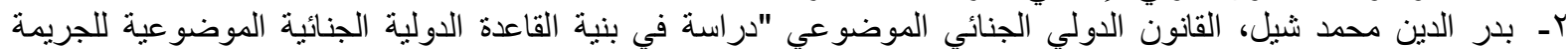

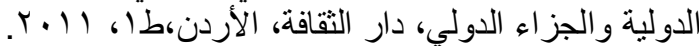

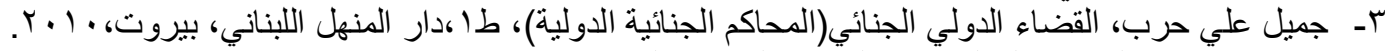

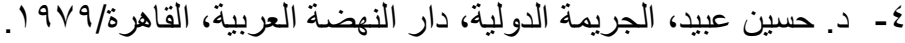

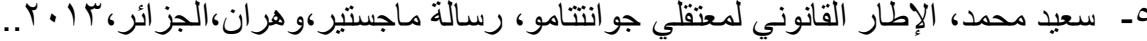

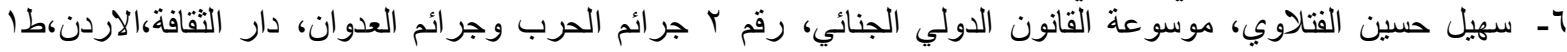
r. 11 ،

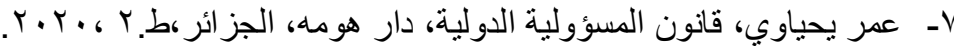

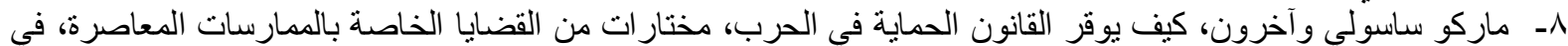

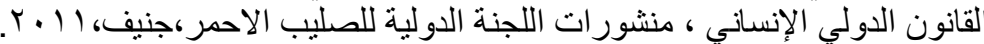
9- ماهر صالح علاوي الجبوري، حقوق الإنسان والطفل والديمقراطية، دار اين الاثثر للطباعة والنشر، الموصل-

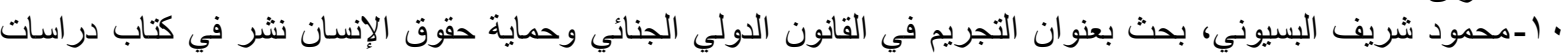

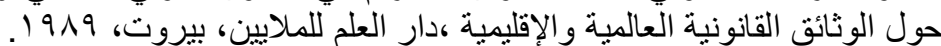
ا اـمحمود شريف بسيوني، المحكمة الجنائية الدولية (مدخل لاربة اسلة أحكام وآليات الإنفاذ الوطني للنظام الأساسي)، دار

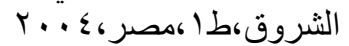

r ا-د. نجية عبد اللطيف، جهود الأمم المتحدة لمكافحة تجنيد الأطفال في النزاعات المسلحة، بحث قانوني منشور في مجلة

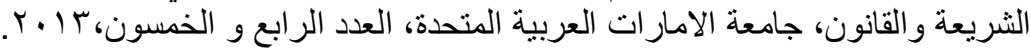

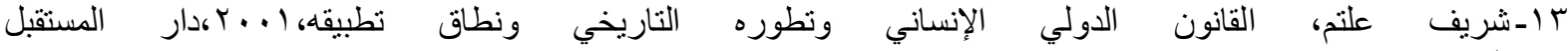

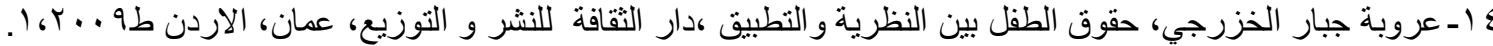

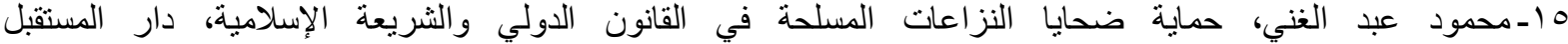

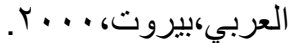

7 ا ـمنال مروان منجد، الطفل في جريمة تجنيد الأطفال بقصد إنر اكهم في أعمال قتالية مجرم أم ضحية، مجلة جامعة دمشق إنق

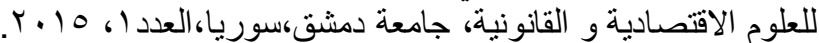

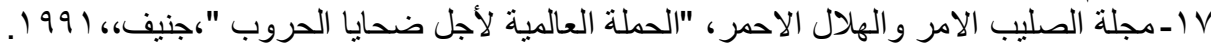

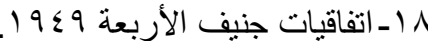

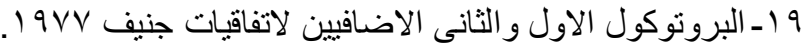

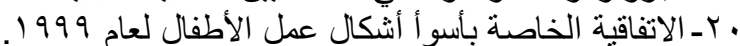

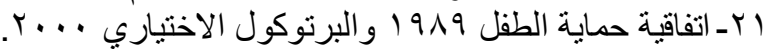

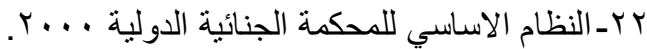
http://www.vrwg.org/downloads/access-25-ar.pdf-rr

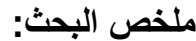

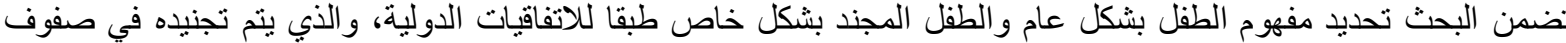

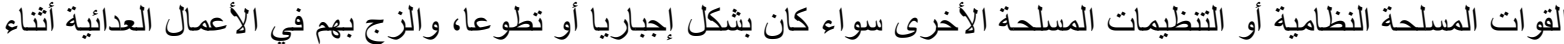
النزاعات المسلحة الدولية أو غير الدولة أو المبات المدول.

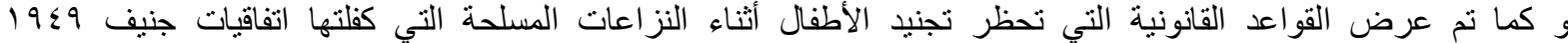

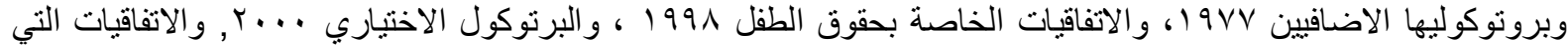

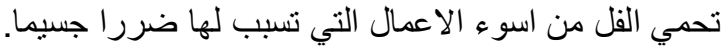
وتبين إن انتهاك قواعد حظر تجنيد الأطفال جريمة حرب متكاملة الأركان، وتقام المسؤولية القانونية امام المحكمة الجنائية 


\section{Abstract}

The research included defining the concept of the child in general and the child soldier in particular in accordance with international conventions, who are recruited into the ranks of the regular armed forces or other armed organizations, whether compulsory or voluntary, and throwing them into hostilities during international armed conflicts or non-state or internationalized.

Also presented were the legal rules prohibiting the recruitment of children during armed conflicts, which were guaranteed by the Geneva Conventions of 1949 and their Additional Protocols 1977, the Conventions on the Rights of the Child 1998, and the Optional Protocol 2000, and the agreements that protect a thousand from the worst acts that cause them serious harm.

Violation of the rules prohibiting the recruitment of children turns out to be an integrated war crime, and legal responsibility lies before the International Criminal Court.

Keywords: children, international conventions, international armed conflicts. 